\title{
Ectopic Vesicular Glutamate Release at the Optic Nerve Head and Axon Loss in Mouse Experimental Glaucoma
}

\author{
Christine T. Fu and David W. Sretavan \\ Neuroscience Graduate Program, Departments of Ophthalmology and Physiology, University of California, San Francisco, San Francisco, California 94143
}

\begin{abstract}
Although clinical and experimental observations indicate that the optic nerve head $(\mathrm{ONH})$ is a major site of axon degeneration in glaucoma, the mechanisms by which local retinal ganglion cell (RGC) axons are injured and damage spreads among axons remain poorly defined. Using a laser-induced ocular hypertension ( $\mathrm{LIOH}$ ) mouse model of glaucoma, we found that within $48 \mathrm{~h}$ of intraocular pressure elevation, RGC axon segments within the $\mathrm{ONH}$ exhibited ectopic accumulation and colocalization of multiple components of the glutamatergic presynaptic machinery including the vesicular glutamate transporter VGLUT2, several synaptic vesicle marker proteins, glutamate, the soluble $\mathrm{N}$-ethylmaleimide-sensitive factor attachment protein receptor complex and active zone cytomatrix components, as well as ultrastructurally identified, synaptophysin-containing vesicles. Ectopic vesicle exocytosis and glutamate release were detected in acute preparations of the LIOH ONH. Immunolocalization and analysis using the ionotropic receptor channel-permeant cation agmatine indicated that $\mathrm{ONH}$ axon segments and glia expressed glutamate receptors, and these receptors were more active after LIOH compared with controls. Pharmacological antagonism of glutamate receptors and neuronal activity resulted in increased RGC axon sparing in vivo. Furthermore, in vivo RGC-specific genetic disruption of the vesicular glutamate transporter VGLUT2 or the obligatory NMDA receptor subunit NR1 promoted axon survival in experimental glaucoma. As the inhibition of ectopic glutamate vesicular release or glutamate receptivity can independently modify the severity of RGC axon loss, synaptic release mechanisms may provide useful therapeutic entry points into glaucomatous axon degeneration.
\end{abstract}

\section{Introduction}

Glaucoma, a progressive neurodegenerative disease affecting an estimated 70 million individuals worldwide (Quigley, 1996), is characterized by visual impairment resulting from optic nerve axon degeneration and retinal ganglion cell (RGC) loss. Substantial evidence indicates that RGC axon dysfunction and degeneration precede cell body loss, and that the optic nerve head (ONH) is an important site of axon injury (Howell et al., 2007; Buckingham et al., 2008; Soto et al., 2008). Previous studies have demonstrated that extensive structural remodeling of axons at the $\mathrm{ONH}$ early in the course of disease manifested as axonal enlargement with accumulation of cellular organelles and obstruction of axonal transport (Anderson and Hendrickson, 1974; Minckler et al., 1976; Quigley and Addicks, 1980; Quigley et al., 1981; Morrison et al., 1997). This disruption of transport is thought to inter-

Received Dec. 30, 2011; revised July 13, 2012; accepted Aug. 1, 2012.

Author contributions: C.T.F. and D.S. designed research; C.T.F. performed research; C.T.F. analyzed data; C.T.F. and D.S. wrote the paper.

This work was supported by NIH Grant EY010688 and EY02162; by an unrestricted grant to the University of California, San Francisco (UCSF) Department of Ophthalmology from Research To Prevent Blindness; and by That Man May See through a gift from Mr. Robert Drabkin. D.S. was the recipient of a Senior Scientific Investigator Award from Research To Prevent Blindness. We thank Larry Ackerman (UCSF Electron Microscopy Lab) for electron microscopy sample processing and coaching; Ivy Hsieh (Cell Imaging Laboratory, Veterans Affairs Medical Center, San Francisco) for assistance with paraphenylenediamine staining; Drs. Richard Palmiter, Larry Zweifel, and Tomas Hnasko for mice; Drs. Zhigang He and Kevin Park for AAV vectors; and Drs. Steven Finkbeiner, Jennifer LaVail, Erik Ullian, and Ben Barres for valuable comments.

Correspondence should be addressed to David W. Sretavan, Department of Ophthalmology, University of California, San Francisco, Box 0730, 10 Koret Way, San Francisco, CA 94143. E-mail: sretavand@vision.ucsf.edu.

DOI:10.1523/JNEUROSCI.0038-12.2012

Copyright $\odot 2012$ the authors $\quad 0270-6474 / 12 / 3215859-18 \$ 15.00 / 0$ fere with the retrograde delivery of trophic support to RGCs, leading to RGC loss (Pease et al., 2000; Quigley et al., 2000; Johnson et al., 2009). While this proposed mechanism of disease has remained a dominant concept in the field, not much attention has been paid to the possibility that injured axons at the $\mathrm{ONH}$ with abnormal accumulation of transported components may give rise to additional local pathophysiological alterations affecting axon survival. In the current study, we present evidence for a novel mechanism in which ectopic neurotransmitter release from injured axon segments at the $\mathrm{ONH}$ and enhanced glutamate receptivity in local cellular elements contribute to axon loss.

\section{Materials and Methods}

Mouse lines. Mice carrying floxed NMDA receptor 1 (NR1; Grin1) gene have been described previously (Tsien et al., 1996). The loxP sequences flank a region of the NR1 gene that encodes the transmembrane domains and the entire $\mathrm{C}$-terminal sequence of the protein. The mice (referred to in this study as NR1-f) were originally maintained in a C57BL/6 background, and were generously donated by Dr. Richard Palmiter at the University of Washington (Seattle, WA).

A conditional allele of the mouse Slc17a6 gene encoding VGLUT2 was generated by engineering two loxP sites surrounding exon 2 (Hnasko et al., 2010). The mice (referred to in this study as VGLUT2-f) were generated by Dr. T. Hnasko while in Dr. R. Palmiter's lab at the University of Washington. The breeding pair in C57BL/6 background used to establish our colony was a gift from Dr. R. Edwards at the University of California, San Francisco (UCSF).

B6 albino mice, B6(Cg)-Tyr $r^{c-2 J} / \mathrm{J}$, were purchased from the Jackson Laboratory (stock number 000058). They are identical to C57BL/6J mice except for a mutation in the tyrosinase gene $\left(T y r^{c-2 J}\right)$. These mice were bred to the black NR1-f and VGLUT2-f mice in the C57BL/6J back- 
ground for two generations to obtain albino floxed transgenics. F2 animals homozygous for both the albinism and floxed loci (Slc17a6 ${ }^{\text {loxP/loxP }}$; $\mathrm{Tyr}^{c-2 J / c-2 J}$ and NR1 ${ }^{\text {loxP/loxP }}$; Tyr ${ }^{c-2 J / c-2 J}$ ) were identified based on coat color and genotyping results.

Additional CD-1 mice were purchased from Charles River Laboratories. All experiments were performed under protocols approved by the UCSF Institutional Animal Care and Use Committee and were in accordance with the Association for Research in Vision and Ophthalmology Statement for the Use of Animals in Ophthalmic and Vision Research.

Laser-induced ocular hypertension. Laser-induced ocular hypertension $(\mathrm{LIOH})$ was performed in male and female CD-1 mice as described previously (Fu and Sretavan, 2010). In most studies, one eye was treated, and the contralateral eye served as a control. In the in vivo glutamate antagonist experiments and adeno-associated virus (AAV) experiments, $\mathrm{LIOH}$ was performed in both eyes to compare the effect of different reagent applications. Intraocular pressure (IOP) was measured with the Tonolab rebound tonometer (Colonial Medical Supply). Only eyes with IOP elevation $>21 \mathrm{~mm} \mathrm{Hg} 1 \mathrm{~d}$ after laser treatment were used for analysis. Mice with overt signs of ocular inflammation were euthanatized and excluded from the study.

To date, we have not obtained consistent and reproducible results with $\mathrm{LIOH}$ induction in C57BL/6 mice. IOP elevation and optic nerve degeneration were observed in some experimental animals, but results were often confounded by considerable anterior segment abnormality and ocular inflammation (data not shown). One major advantage of using albino mice for $\mathrm{LIOH}$ is the ease of visualizing ocular vasculature, allowing better laser targeting and minimal secondary damage. Therefore, NR1-f and VGLUT2-f mice originally maintained in the C57/BL6 background were crossed to the coisogenic albino strain $\mathrm{B} 6(\mathrm{Cg})-\mathrm{Tyr}^{c-2 J} / \mathrm{J}$ (The Jackson Laboratory). Albino offspring obtained after two generations were used in $\mathrm{LIOH}$ experiments. For B6 albino mice, a $50 \mu \mathrm{m}$ instead of $100 \mu \mathrm{m}$ spot size was used to photocoagulate the episcleral veins, while all other aspect of the protocol remained identical to that for CD-1 (Fu and Sretavan, 2010).

Immunohistochemistry. Samples for immunohistochemistry were processed as described previously (Fu and Sretavan, 2010) unless stated otherwise below. Briefly, mice were deeply anesthetized and perfused transcardially with $4 \%$ PFA in $0.1 \mathrm{~m}$ PBS, pH 7.4. Eye cups consisting of the retina and a segment of retrobulbar optic nerve were dissected out, immersion fixed in the same fixative at room temperature for $2 \mathrm{~h}$, and cryoprotected with $30 \%$ sucrose. Eye cups were then embedded in Tissue-Tek optimal cutting temperature compound (Sakura Finetek), and $12 \mu \mathrm{m}$ cryosections were cut along the longitudinal axis through the ONH. Sections were mounted on Super Frost Plus slides (Fisher Scientific).

Before immunostaining, cryosections were air dried at room temperature for $1 \mathrm{~h}$ and washed with $0.1 \mathrm{M}$ PBS. Nonspecific binding was blocked with $10 \%$ normal donkey serum (NDS) for $1 \mathrm{~h}$ at room temperature. Triton X-100 (0.1\%) was included in the blocking solution to permeabilize the tissues. Primary antibody (diluted in 1\% NDS) incubation at $4^{\circ} \mathrm{C}$ overnight was followed by PBS washes and secondary antibody incubation for $1 \mathrm{~h}$ at room temperature. Slides were then mounted in Vectashield mounting medium (Vector Laboratories) and examined with confocal microscopy. All immunostaining was performed with the appropriate controls omitting primary antibodies, and dilution series were performed with both the primary and secondary antibodies to identify optimal parameters for fluorescence detection.

For glutamate immunohistochemistry, eye cups were dissected from deeply anesthetized mice and fixed in $4 \%$ PFA with $2 \%$ glutaraldehyde in $0.1 \mathrm{~m}$ phosphate buffer (PB), $\mathrm{pH} 7.4$, for $30 \mathrm{~min}$ at $4^{\circ} \mathrm{C}$. Cryosections were blocked in $6 \%$ NDS with $0.3 \%$ Triton $\mathrm{X}-100$ for $1 \mathrm{~h}$ at room temperature, followed by anti-glutamate antibody incubation in $3 \% \mathrm{NDS}$ at $4^{\circ} \mathrm{C}$ overnight. All washes were performed in PB with $0.05 \%$ Tween-20.

The glutamate receptor antibodies (GluR1, GluR2, and NR1) were found to be sensitive to fixation and permeabilization conditions, in agreement with previous observations (Fletcher et al., 2000; Haverkamp and Wassle, 2000). With long fixation and harsh detergent treatment, the punctate staining pattern of receptors was greatly diminished. We fixed freshly dissected eye cups with $4 \%$ PFA in $0.1 \mathrm{M} \mathrm{PB}$, pH 7.4, for only 15 min on ice, before cryoprotection and embedding. Blocking and antibody incubation were performed without Triton X-100 permeabilization.

The primary antibodies used in the immunohistochemical studies are as follows, with the dilution given in parentheses: rabbit anti-VGLUT2 (1:400), rabbit anti-synaptotagmin-1, lumenal and cytoplasmic domains (1:100) from Synaptic Systems; mouse anti-SV2 (1:200) from the Developmental Studies Hybridoma Bank (University of Iowa, Iowa City, IA); rabbit anti-synaptophysin (1:300), rabbit anti-glutamate (1:50), rabbit anti-GluR1 (1:500), mouse anti-GluR2 (1:500), rabbit anti-NR1 (AB1516; 07-362-MN; 1:100), rabbit anti-agmatine (AGB; 1:300), and mouse anti-NeuN (1:500) from Millipore; mouse anti-NR1 (1:500) from BD PharMingen; mouse anti-Bassoon (1:200) from StressGen; mouse anti-GFAP (1:400) from Millipore; rabbit anti-green fluorescent protein (GFP; Alexa Fluor 488-conjugated; 1:100) from Invitrogen; mouse anti-tubulin $\beta$-III (1:500) and mouse anti-synaptosomal-associated protein 25 (SNAP-25) (1:500) from Covance Research Products; and rabbit anti-VAMP2 (1:500) from Abcam. Secondary antibodies used for colabeling experiments were conjugated to cy3 and cy5 fluorescent dyes (1:200; Jackson ImmunoResearch). These two fluorophores were chosen for maximal spectral separation. Most images were colorized in green and red for consistency of presentation and ease of visualizing colocalization. For triple labeling, cy2 was also used.

Quantification of fluorescence in confocal images. Fluorescence images were collected on an inverted confocal laser microscope (LSM5 Pascal; Carl Zeiss Meditec). Laser wavelengths at 488, 543, and $633 \mathrm{~nm}$ were used to excite cy2, cy3, and cy5, respectively. During image acquisition, parameters were carefully monitored with a Range Indicator Lookup Table to ensure that pixels were neither saturated nor too dark. In experiments comparing signal intensity between different treatment groups, all samples were processed in parallel and imaged under identical microscope settings. The mean pixel intensity over randomly selected regions of interest (ROIs) was measured using Image $(\mathrm{NIH})$ and averaged across at least three sections for each sample.

Quantitative colocalization analysis. Quantitative colocalization analysis was performed based on the Costes et al. (2004) method using ImageJ. For each dual-channel image, colocalization was first confirmed or rejected using the Costes et al. (2004) randomization method. The software tests Pearson's correlation coefficient $(r)$ against 25 iterations in which the pixel values in one channel are scrambled to simulate random overlap, and then derives a $p$ value for the probability of colocalization. For $p$ values of $>95 \%$, the colocalization is considered significant. Images from multiple experiments were analyzed quantitatively and used to compute a mean value of the Pearson's coefficient.

Dot blot analysis. The unmyelinated $\mathrm{ONH}$ tissues were carefully dissected from freshly harvested eye cups and immediately placed in microcentrifuge tubes on dry ice to snap freeze. Ten ONHs were pooled as one sample, and three samples each from control and LIOH-treated group were analyzed. After the addition of $50 \mu$ lice-cold extraction buffer $(1 \%$ Triton X-100, $200 \mathrm{~mm} \mathrm{NaCl}, 25 \mathrm{~mm}$ Tris-Cl at pH7.4) supplemented with protease inhibitor cocktail (Roche Applied Science), each sample was homogenized with a small pestle designed for microcentrifuge tubes. The homogenate was centrifuged at $12000 \mathrm{rpm}$ for $20 \mathrm{~min}$ at $4^{\circ} \mathrm{C}$. The Bradford assay was performed on the collected supernatant to determine total protein concentration. After matching the concentration between samples by dilution, $2 \mu \mathrm{l}$ of each protein extract was spotted on a nitrocellulose membrane, dried, and blocked with $5 \%$ nonfat milk for $1 \mathrm{~h}$ each at room temperature, and then probed with the appropriate antibody overnight at $4^{\circ} \mathrm{C}$. The membrane was washed in Tris-buffered saline containing $0.05 \%$ Tween-20, and incubated with horseradish peroxidase (HRP)-conjugated secondary antibodies. The immunoreactive signals were visualized using a chemiluminescence kit (Immun-Start WeternC; Bio-Rad Laboratories), and the mean pixel intensity within the entire dot blot was quantified using Photoshop CS4 (Adobe). Glyceraldehyde phosphate dehydrogenase (GAPDH) was reported to show no significant expression change in a rat glaucoma model (Johnson et al., 2007) and was therefore chosen as a loading control processed in parallel with the proteins of interest using identical procedures. 
The following primary antibodies were used in the dot blot analysis: mouse anti-SV2 (1:100; Developmental Studies Hybridoma Bank), rabbit anti-synaptophysin (1:300; Millipore), rabbit anti-VGLUT2 (1:1000; Synaptic Systems), mouse anti-Bassoon (1:250; StressGen), mouse antiSNAP-25 (1:1000; Covance Research Products), mouse anti-NR1 (1:400; BD PharMingen), and HRP-conjugated anti-GAPDH (1:5000, Abcam). HRP-conjugated secondary antibodies were obtained from Jackson ImmunoResearch: goat anti-mouse $\operatorname{IgG} / \operatorname{IgM}(1: 5000)$ and donkey antirabbit IgG (1:5000).

Immunoelectron microscopy. Mice were anesthetized and perfused with $4 \%$ paraformaldehyde and $2 \%$ glutaraldehyde in $0.1 \mathrm{M} \mathrm{PB}, \mathrm{pH} 7.4$. ONH tissues were dissected, postfixed in $2 \%$ osmium tetroxide for $1 \mathrm{~h}$ followed by $2 \%$ uranyl acetate, dehydrated in an ascending series of alcohol washes, and embedded in epoxy resin. Ultrathin sections $(80 \mathrm{~nm})$ were collected on nickel grids covered with a Butvar support film and stained with synaptophysin antibodies (1:300; Millipore). Bound primary antibodies were detected with goat anti-rabbit IgG conjugated to $10 \mathrm{~nm}$ gold particles (Aurion). Sections were examined and photographed with a JEOL 100CX-II microscope at an accelerating voltage of $80 \mathrm{kV}$.

Synaptotagmin labeling assay. Mice were euthanized with pentobarbital, and the eyes with optic nerve attached were removed and placed into ice cold HEPES-buffered artificial CSF (ACSF) containing the following (in $\mathrm{mm}$ ): $140 \mathrm{NaCl}, 3 \mathrm{KCl}, 1 \mathrm{MgCl}_{2}, 1 \mathrm{CaCl}_{2}, 10$ HEPES, and 10 glucose, $\mathrm{pH}$ 7.4. A 5-mm-long segment of optic nerve was isolated intact to minimize antibody reaching the $\mathrm{ONH}$ via diffusion through the cut end. The meninges encasing the nerve were carefully dissected away to enable reagent penetration. The cornea and iris were removed, while the lens was left in place to maintain the shape of eye cup until after fixation. Dissected eye cup/optic nerve preparations were transferred into preequilibrated bicarbonate-buffered ACSF containing the following (in mM): $126 \mathrm{NaCl}, 3 \mathrm{KCl}, 2 \mathrm{CaCl}_{2}, 2 \mathrm{MgSO}_{4}, 1.25 \mathrm{NaH}_{2} \mathrm{PO}_{4}, 26 \mathrm{NaHCO}_{3}$, and 10 glucose, $\mathrm{pH}$ 7.4. The samples were incubated in a standard $37^{\circ} \mathrm{C}$ cell culture incubator for $1 \mathrm{~h}$. In the no-stimulation experiment, normal ACSF was used. In the high $\mathrm{K}^{+}$-stimulation condition, $\mathrm{NaCl}$ was replaced with $40 \mathrm{~mm} \mathrm{KCl} . \mathrm{K}^{+}$containing $\mathrm{Ca}^{2+}$-free solution $\left(\mathrm{K}^{+} / 0 \mathrm{Ca}^{2+}\right)$ was made from this $\mathrm{K}^{+}$stimulation buffer by omitting $\mathrm{CaCl}_{2}$ and adding $1 \mathrm{~mm}$ EGTA. In the hypertonic sucrose condition, $800 \mathrm{~mm}$ sucrose was added. After incubation, the samples were washed in HEPES-buffered ACSF, and incubated with lumenal domain (SYT-lum) or cytoplasmic domain (SYT-cyto) synaptotagmin antibodies (1:100; Synaptic Systems) in HEPES-buffered ACSF on ice for $8 \mathrm{~h}$. This temperature was chosen to minimize uptake of antibodies into the axons by endocytic means. Following washing, labeled tissues were fixed in $4 \%$ PFA at room temperature for $30 \mathrm{~min}$ and processed for cryosectioning as described previously. The eye cups were cut into $12 \mu \mathrm{m}$ longitudinal sections, and every third one was collected onto the same slide. Only sections through the $\mathrm{ONH}$ were kept, yielding five sections per slide to be analyzed. Nonspecific binding was blocked by $10 \%$ NDS for $1 \mathrm{~h}$ at room temperature, without detergent permeabilization. Detection of bound synaptotagmin antibodies was performed by incubation with cy3-conjugated secondary antibodies (Jackson ImmunoResearch). As negative controls, tissues were incubated with secondary antibodies or dextran-conjugated (3000 molecular weight) tetramethylrhodamine to rule out nonspecific uptake of reagents into the axoplasm. No staining was found in negative controls.

Fluorescence images were acquired by confocal microscopy and analyzed with ImageJ (NIH). Some nonspecific staining of blood vessels at the $\mathrm{ONH}$ was observed, which was clearly distinguishable from axonal labeling. Four $50 \times 50 \mu \mathrm{m}$ ROIs were placed over each image, avoiding inclusion of blood vessels in the analysis. Mean pixel intensity was measured and averaged across the ROIs. In most cases, five sections were analyzed and averaged for each eye sample. To allow for direct comparison of different experiments, data in each experiment were normalized against the SYT-cyto control (no-LIOH) sample for Figure 4, E and F. For Figure $4 G$, only LIOH samples were studied using SYT-lum, and data were normalized against the no stimulation condition.

Glutamate detection with NADH assay. ONH tissues were quickly dissected in HEPES-buffered ACSF and cut into halves along the longitudinal axis. One-half of the tissue was immobilized with a slice anchor in the imaging chamber and bathed in an enzymatic assay solution composed of the following (in mM): $120 \mathrm{NaCl}, 2.6 \mathrm{KCl}, 1 \mathrm{MgCl}_{2}, 2.5 \mathrm{CaCl}_{2}, 1$ D-aspartic acid, 10 HEPES, and 10 glucose, supplemented with $\beta$-nicotinamide adenine dinucleotide $\left(\mathrm{NAD}^{+} ; 4 \mathrm{~mm}\right.$; Roche Applied Science) and L-glutamic dehydrogenase (GDH; $60 \mathrm{~mm}$; Roche Applied Science), $\mathrm{pH}$ 7.4. Imaging experiments were performed at room temperature on an inverted microscope (TE300; Nikon) equipped for epifluorescence microscopy. Excitation from a xenon arc lamp was filtered through an ultraviolet filter set (UV-2E/C; Nikon). Fluorescence images were captured at 1 min intervals using a CCD camera (Retiga EXi; QImaging) controlled by SimplePCI software (Hamamatsu). After equilibration of tissue in the enzymatic solution for $\sim 3 \mathrm{~min}$, baseline fluorescence images were collected for 5-6 min, followed by bath stimulation with an assay solution containing high $\mathrm{K}^{+}$(substituting $\mathrm{NaCl}$ in the previous buffer with $100 \mathrm{mM} \mathrm{KCl}$ ) or hypertonic sucrose (addition of 800 $\mathrm{mm}$ sucrose). Image acquisition continued for another $10 \mathrm{~min}$ after stimulation. Data were processed using the NIH ImageJ software. Raw images were corrected for photobleaching using the "bleach correction" plug-in for ImageJ. The exponential decay constant was calculated from control experiments in which tissues were imaged without stimulation. Following background subtraction, five ROIs were randomly selected over the $\mathrm{ONH}$ in each image. The mean pixel intensity in these ROIs was measured and averaged. To compare experiments conducted on different days, the change in fluorescence was expressed as $\Delta F / F_{0}$, in which $F_{0}$ was the baseline fluorescence, and $\Delta F$ was the change in fluorescence intensity at each time point after stimulation (Innocenti et al., 2000). Statistical analysis was performed using two-way ANOVA followed by Bonferroni post tests.

AGB activation assay. Anesthetized mice received bilateral $20 \mu \mathrm{l}$ injection of $25 \mathrm{~mm}$ AGB (Sigma) into the subconjunctival space. This method delivered AGB to the $\mathrm{ONH}$ to examine ionotropic glutamate receptor activation in vivo. After $2 \mathrm{~h}$ of survival time, eye cups were quickly dissected, washed briefly in HEPES-buffered ACSF, and fixed in 4\% PFA with $0.01 \%$ glutaraldehyde in $0.1 \mathrm{M} \mathrm{PB}, \mathrm{pH} 7.4$, for $30 \mathrm{~min}$ at $4^{\circ} \mathrm{C}$. After washing for $15 \mathrm{~min}$ in $\mathrm{PB}$ at room temperature with shaking, the eye cups were processed for anti-agmatine immunohistochemistry. Cryosections were blocked in $6 \%$ NDS with $0.5 \%$ Triton X-100 for $1 \mathrm{~h}$ at room temperature, followed by primary antibody (anti-agmatine; 1:300; Millipore) incubation in $3 \%$ NDS and $0.5 \%$ Triton X-100 at $4^{\circ} \mathrm{C}$ overnight.

Fluorescence confocal images were analyzed with ImageJ (NIH). Identical parameters were used to set the threshold of fluorescence for the control and treatment groups. Area of the AGB signal in each $\mathrm{ONH}$ section was then measured and averaged. Data from the LIOH-treated ONHs were normalized against the contralateral control sample from the same animal. For the AAV experiments, only AGB signal in axons was quantified. To do this, sections were coimmunostained for AGB and tubulin. The image channel containing tubulin immunoreactivity was binarized and used to create a mask, within which AGB-positive area was measured. The data were then calculated as the area of AGB immunoreactivity divided by tubulin immunoreactivity to obtain a measure of the extent of AGB activation within axons. Results from each pair of AAVinjected eyes were normalized against the AAV-GFP condition.

In vivo glutamate antagonist treatment. Mice were anesthetized $1 \mathrm{~d}$ after LIOH treatment. The conjunctiva was surgically opened, and the optic nerve was exposed by retracting intraocular muscles with blunt forceps. A small piece of gel foam soaked in $3 \mu \mathrm{l}$ of reagents was locally delivered to the $\mathrm{ONH}$ and held in place underneath intraocular muscle fibers. One eye was treated with a drug mixture containing NBQX (500 $\mu \mathrm{M}$; Tocris Bioscience), MK-801 (500 $\mu \mathrm{M}$; Tocris Bioscience), and tetrodotoxin (TTX; $300 \mu \mathrm{m}$; Tocris Bioscience), whereas vehicle was delivered to the fellow eye. Bacitracin antibiotic ointment was administered after surgery, and any animal with postoperative eye infection was excluded from the study. Optic nerves were harvested $6 \mathrm{~d}$ after surgery and analyzed by counting axons in paraphenylenediamine (PPD)-stained tissue cross-sections. The PPD staining and axon counting procedures have been described in detail in previous studies (Fu and Sretavan, 2010, 2011).

Recombinant AAV vectors. The Cre- or GFP-expressing recombinant AAV (rAAV) vectors were generous gifts from Dr. Z. He (Harvard Medical School, Boston, MA). They were constructed by inserting Cre recom- 
binase or GFP cDNA into the pAAV-MCS plasmid containing AAV2 inserted terminal repeats (Stratagene) as described previously (Park et al., 2008). Viral particles were produced, purified, and titered by the University of North Carolina Vector Core Facility (Chapel Hill, NC).

Intravitreal injection. Albino floxed mice were anesthetized with ketamine and xylazine. One eye was injected intravitreally with $1 \mu \mathrm{l}$ of AAV vector carrying the Cre recombinase (AAV-Cre; $2 \times 10^{12}$ particles $/ \mathrm{ml}$ ), and the fellow eye was injected with AAV-GFP control $\left(1.5 \times 10^{12}\right.$ particles $/ \mathrm{ml}$ ). The eye was first punctured lightly with a 30 gauge hypodermic needle just behind the ora serrata. A custom-made 32 gauge needle attached to a $10 \mu$ l syringe (Hamilton) was then inserted into the vitreous cavity and angled carefully to avoid damaging the lens. Viral particles were dispensed slowly over $1 \mathrm{~min}$, after which the needle was left in place for an additional minute to allow for diffusion of the virus. Three weeks following viral injection, $\mathrm{LIOH}$ was performed on both eyes of the injected mice.

Statistical analysis. The synaptotagmin assay data were evaluated with one-way ANOVA followed by Tukey's multiple comparison test. Data from the NADH assays and axon counting in AAV experiments were analyzed with two-way ANOVA followed by Bonferroni's post hoc multiple comparison test. Results from the AGB assays, in vivo glutamate antagonist treatments, and analysis of VGLUT2/glutamate level in AAV experiments were evaluated by $t$ test. Statistical analysis was performed using the GraphPad Prism (version 5) software, with the significance level set at $p<0.05$. Values are reported as mean \pm SEM.

\section{Results}

\section{Early ectopic accumulation of synaptic vesicle components within axons at the $\mathrm{LIOH}$-treated $\mathrm{ONH}$}

The ONH is normally a nonsynaptic region without any apparent accumulation of the molecular components associated with synapses. However, within $2 \mathrm{~d}$ after the laser induction of experimental glaucoma and elevation of IOP, multiple presynaptic makers were highly concentrated at the $\mathrm{ONH}$, including synaptic vesicle (SV) proteins SV2 and synaptophysin (Fig. 1A), vesicular glutamate transporter VGLUT2 (Fig. $1 A$ ), v-SNARE protein VAMP2 (Fig. $1 B$ ), and active zone cytomatrix component Bassoon (Fig. $1 B$ ). In addition, the t-SNARE protein SNAP-25 was found to be present at the ONH of both control and LIOHinduced animals (Fig. $1 B$ ). The patterns of immunoreactivity of these markers varied in size, ranging from intensely stained large axon bundles (Fig. 1B, rectangular dashed box), to smaller "hot spots" interspersed along the axons like beads on a string (Fig. $1 B$, dashed oval). The distribution of axon bundles containing synaptic vesicle components was highly heterogeneous within the $\mathrm{ONH}$, with affected axon bundles located next to others that were seemingly unaffected. Furthermore, within many axons, synaptic component immunoreactivity was present in foci instead of being uniformly distributed along the entire axon length (Fig. 1C). The accumulation of all markers except for SNAP-25 after LIOH treatment was mainly localized to the unmyelinated $\mathrm{ONH}$, compared to the retina or myelinated optic nerve. Quantification of SV2 fluorescence intensity indicated that the ratio of $\mathrm{LIOH}$ versus control was $2.7 \pm 0.7$ for the retinal gangling cell layer, $33.1 \pm 7.3$ for the $\mathrm{ONH}$, and $5.7 \pm 0.9$ for the adjacent optic nerve region $(p<0.0001 ; n=10)$.

The accumulation of these synapse-associated components was demonstrated in repeated experiments, $(>60$ times for SV2, $>20$ times for synaptophysin, $>30$ times for VGLUT2, $>6$ times for Bassoon, 3 times for VAMP2, and $>12$ times for SNAP-25). This phenomenon was observed starting as early as $2 \mathrm{~d}$ after $\mathrm{LIOH}$ and persisted beyond 2 weeks. As the intensity of labeling tended to diminish after $4 \mathrm{~d}$, most experiments in this study were performed on samples harvested between 2 and $4 \mathrm{~d}$ after LIOH.
The cellular origin of the VGLUT2 signal was determined in colabeling experiments simultaneously visualizing VGLUT2, tubulin $\beta$-III as a neuron-specific axonal marker (Watanabe et al., 1991; Brown et al., 2001), and GFAP as an astrocytic marker (Fig. $1 C)$. Upon visual inspection, VGLUT2 immunoreactivity was colocalized with $\beta$-III tubulin (Fig. $1 C$, arrowheads) but not GFAP (Fig. 1C, arrows). Quantitative colocalization analysis was performed in dual-channel images with an ImageJ plug-in, which scrambles the pixel values in one channel to simulate random overlap and compares it to the original image. This randomization algorithm was iterated 25 times, and $p>95 \%$ was used as a criterion to confirm significant colocalization. Multiple experiments were analyzed, and the Pearson's coefficient $(r)$ is reported as mean \pm SEM. Significant colocalization was confirmed for VGLUT2 and tubulin colabeling $(p>95 \% ; r=0.61 \pm 0.03 ; n=$ $6)$. No colocalization was found between VGLUT2 and GFAP $(p<95 \% ; r=-0.05 \pm 0.01 ; n=6)$. These data indicate that ectopic VGLUT2 accumulation after LIOH was present in RGC axons at the ONH rather than astrocytes. SV2 and synaptophysin immunoreactivities at the $\mathrm{ONH}$ were also found to have the same patterns of axonal localization (Fig. $1 E$ ).

Similar colocalization studies with VGLUT2 and putative active zone markers revealed that the majority of ONH VGLUT2 immunoreactivity overlapped with SNAP-25 (Fig. 1D, merged image, arrowheads), although SNAP-25 was more widely distributed (Fig. $1 D$, arrow), consistent with its expression even in control RGC axons. Occasional spots of VGLUT2 immunoreactivity were not colabeled with SNAP-25 (Fig. 1 D, double arrows), perhaps corresponding to severely degenerating axonal segments. The majority of VGLUT2 similarly colocalized with Bassoon (Fig. $1 D$, inset, arrowheads); however, hot spots predominantly immunoreactive for VGLUT2 (Fig. 1D, inset, arrow) or Bassoon (Fig. $1 D$, inset, double arrow) were also found. Quantitative analysis confirmed significant colocalization of VGLUT2 with both SNAP-25 $(p>95 \% ; r=0.80 \pm 0.03 ; n=6)$ and Bassoon $(p>$ $95 \% ; r=0.79 \pm 0.04 ; n=6)$.

The increased presence of these SV components demonstrated in immunohistochemical studies was confirmed in immunoblotting experiments. Due to the difficulty of performing electrophoresis and Western transfer with very small amounts of tissue from a single $\mathrm{ONH}$, we pooled $10 \mathrm{ONH}$ into one sample and used a dot blot method to achieve protein detection. Dot blot analysis for each SV component compared tissue samples from control and LIOH animals and was repeated three times. Dot blot signal intensity was quantified and corrected against GAPDH loading controls (Fig. 2). In agreement with immunohistochemical data, significant increases in $\mathrm{ONH}$ protein expression was found for SV2 (fivefold; $p=0.04$ ), synaptophysin (threefold; $p=$ 0.01 ), VGLUT2 (threefold; $p=0.001$ ), and Bassoon (fivefold; $p=0.04$ ) after LIOH treatment. SNAP-25 level was also slightly increased, but the difference was not statistically significant (0.6fold; $p=0.2$ ).

\section{Ultrastructural localization of synaptophysin to vesicle-like structures in axons}

Postembedding immunoelectron microscopy (immuno-EM) was performed to examine the ultrastructural localization of the ONH synaptic vesicle proteins observed at the light microscopy level. Contrary to the orderly array of tightly packed RGC axons in the control ONH (Fig. $3 A$ ), previous work has shown that experimental glaucoma results in the disorganization of $\mathrm{ONH}$ axon fibers (Morrison et al., 1997; Pease et al., 2000), a finding confirmed by the current ultrastructural analysis. The present 
A
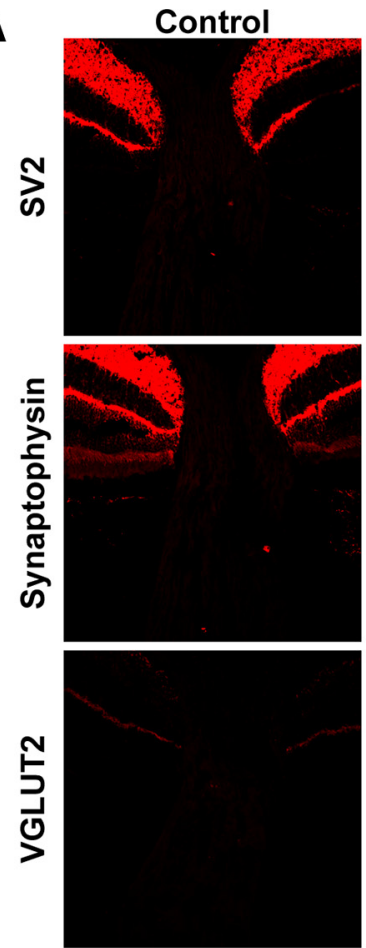

C
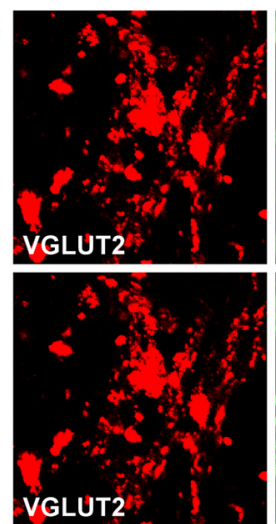

D
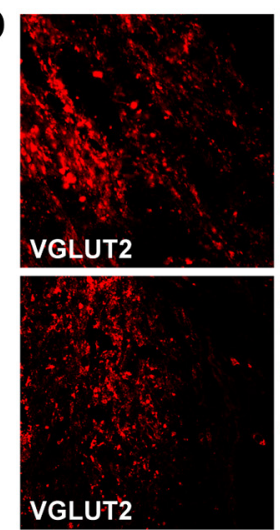
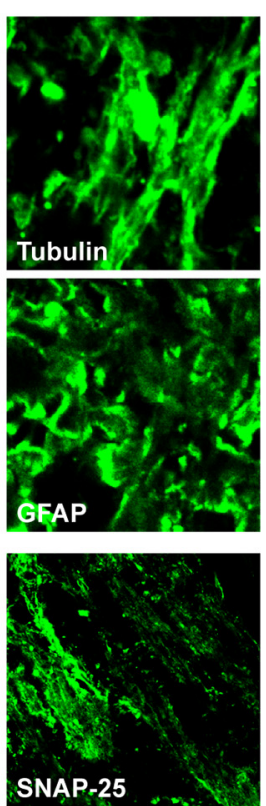

(x)

W.

S.t.
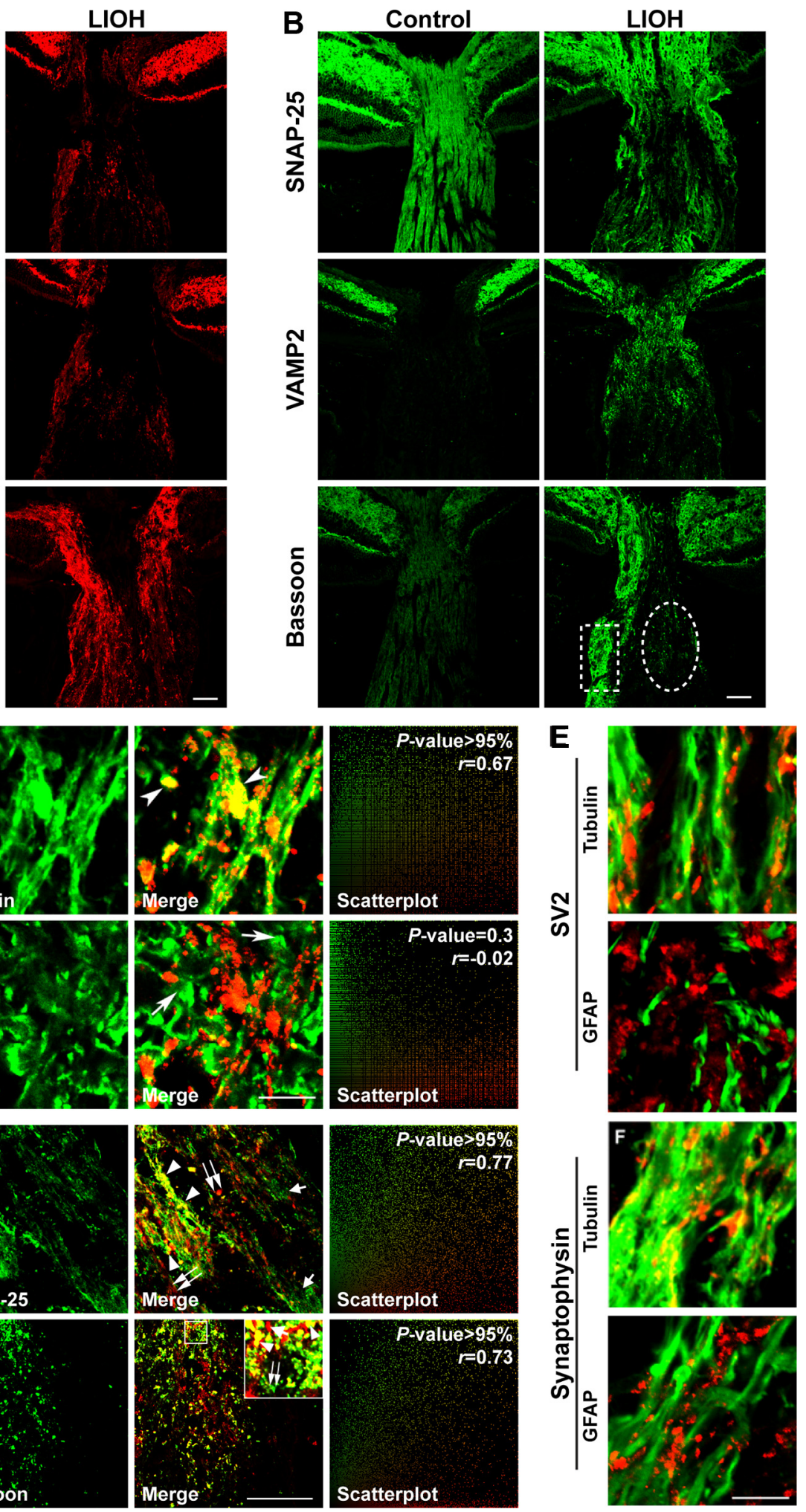

Figure 1. Ectopic accumulation of presynaptic markers at the $\mathrm{ONH}$ after $\mathrm{LIOH}$. $A$, Frozen sections of control and $\mathrm{LIOH}$ eye cups were immunostained with antibodies against synaptic vesicle proteins, including SV2, synaptophysin, and VGLUT2. All three markers show only faint and diffuse staining in the optic nerve of controls, but exhibited increased accumulation at the ONH of LIOH samples (shown here at $4 \mathrm{~d}$ after treatment). Comparable levels of labeling in the retina confirmed that the control and LIOH samples were processed identically. B, SNAP-25, VAMP2, and Bassoon were present at the LIOH ONH and partially overlapped with VGLUT2. SNAP-25 was expressed in both control and LIOH optic nerve. VAMP2 and Bassoon labeling was weak in the control optic nerve, but became strongly upregulated after $\mathrm{LIOH}$. Rectangular and oval dashed boxes denote large immunoreactive axon bundles and smaller hot spots, respectively. $C$, Eye cup sections collected $4 \mathrm{~d}$ after LIOH were immunostained for VGLUT2, tubulin $\beta$-III, and GFAP. Regions within the ONH were imaged in triple channels. Ectopic VGLUT2 was observed to colocalize with the axonal marker tubulin (arrowheads) but not the astrocytic marker GFAP (arrows). Six experiments were analyzed quantitatively and used to compute a mean value of the Pearson's coefficient ( $r$ ) as a measure of colocalization. For VGLUT2 and tubulin, significant colocalization was determined ( $p>95 \% ; r=0.61 \pm 0.03$ ). For VGLUT2 and GFAP, no colocalization was found ( $p<95 \% ; r=-0.05 \pm$ 0.01). A representative experiment is shown here with the corresponding scatterplots and $r$ values. $\boldsymbol{D}$, Colabeling of VGLUT2 and SNAP-25 showed that the two markers overlapped extensively (arrowheads), although some areas were only labeled for SNAP-25 (arrows) or VGLUT2 (double arrows). Colabeling of VGLUT2 and Bassoon (Figure legend continues.) 


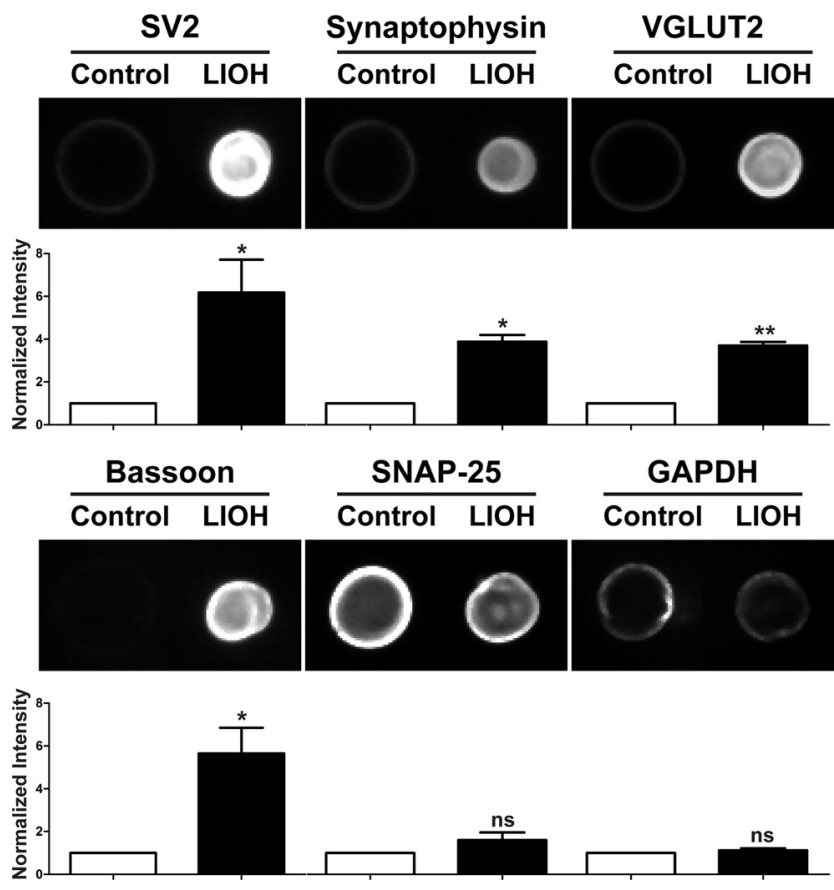

Figure 2. Immunodot blot analysis of presynaptic protein levels. Each animal was subjected to $\mathrm{LIOH}$ in one eye, and the contralateral eye was left untreated as a control. Each control or $\mathrm{LIOH}$ sample contained pooled protein extract from $10 \mathrm{ONHs}$. Chemiluminescence signals were quantified, corrected against the GAPDH loading control, and plotted as $\mathrm{LIOH}$ normalized against the non-LIOH control. SV2, synaptophysin, VGLUT2, and Bassoon all demonstrated significant $\mathrm{ONH}$ accumulation following $\mathrm{LIOH}$. The change in SNAP-25 level was not significant (ns). ${ }^{*} p<0.05 ;{ }^{* *} p<0.01$.

study also revealed the presence of large axonal swellings with accumulation of membrane-bound organelles at the LIOH-treated ONH such as mitochondria, multilamellar bodies, translucent vesicles, and dense core vesicles (Figs. $3 B, C$ ). The morphology of the vesicles differed from the small spherical vesicles found at classical synapses, which mature in the axonal terminals and are more uniform in size. The vesicles encountered in $\mathrm{ONH}$ axons after $\mathrm{LIOH}$ were more variable in size and shape, measuring $64.0 \pm 15.9 \mathrm{~nm}$ in length and $50.2 \pm 13.0 \mathrm{~nm}$ in width.

The molecular characteristic of these vesicular structures was investigated using immuno-EM. Synaptophysin was chosen as a representative synaptic vesicle marker based on the availability of antibody reagents. In ONH sections from control animals, only sparse gold particles were observed (Fig. 3D, medium magnification), and individual translucent vesicles associated with immunogold labeling were only occasionally found in the axons (Fig. 3G, high magnification, arrow). In LIOH-treated ONH samples, the translucent vesicles were strongly labeled with gold particles (Fig. $3 E, F$, arrows, medium magnification; $H$, high magnification),

$\leftarrow$

(Figure legend continued.) was imaged from an $0 \mathrm{NH}$ region similar to the dashed oval in $\boldsymbol{B}$. A large proportion of Bassoon and VGLUT2 immunoreactive hot spots overlapped in the merged image. The inset is a high-magnification image taken from the boxed region, showing examples of colocalization (arrowheads) as well as hot spots predominantly labeled for VGLUT2 (arrow) or Bassoon (double arrow). For VGLUT2 and SNAP-25, 12 experiments were examined, and 6 were subjected to quantitative analysis ( $p>95 \% ; r=0.80 \pm 0.03$ ). For VGLUT2 and Bassoon, 6 experiments were quantitatively analyzed ( $p>95 \% ; r=0.79 \pm 0.04)$. $E$, Top two panels, Colocalization of SV2 (red) with $\beta$-III tubulin (green), but not with GFAP (green). Bottom two panels, Colocalization of synaptophysin (red) with $\beta$-III tubulin (green), but not with GFAP (green). Scale bars, $50 \mu \mathrm{m}$. suggesting that they contained synaptophysin. Synaptophysincontaining vesicles were often found abutting the axolemma (Fig. $3 \mathrm{H}$, arrows). Patches of electron-dense material were sometimes observed along the plasma membrane, reminiscent of the cytomatrix of active zones (Fig. $3 F, H$, arrowheads). Intense immunogold labeling was also noted along the axolemma of some axons (Fig. 3I, arrows). We did not observe specializations resembling postsynaptic densities.

The distribution of vesicle-containing axonal swellings demonstrated cellular and subcellular heterogeneity (Fig. $3 B, C, E, F$ ). Axons with swollen segments were often found adjacent to structurally normal fibers. Furthermore, within a given axon, swollen segments were located next to segments of relatively normal morphology. These swellings may correspond with the heterogeneous hot spots observed in light microscopy following immunostaining using synaptic vesicle markers.

Together, the data presented thus far indicate that an accumulation of vesicle-like structures containing synaptic vesicle proteins was present within axon segments at the $\mathrm{ONH}$ within $48 \mathrm{~h}$ after IOP elevation. Furthermore, the colocalization of synaptic vesicle proteins such as SV2, synaptophysin, and VGLUT2 with Bassoon and SNAP-25 raised the possibility that such vesicle-like structures may have access to SNARE and the cytomatrix at the active zone machinery, which normally mediate vesicle fusion with the axolemma.

\section{Ectopic ONH vesicle exocytosis}

To investigate whether exocytosis of ectopic vesicles can occur at the LIOH-treated ONH, we used two antibodies, one specific for the lumenal domain and the other for the cytoplasmic domain of synaptotagmin-1, both of which have been used in studies of exocytic events (Matteoli et al., 1992; Kraszewski et al., 1995). Following SV exocytosis in live neurons, the lumenal epitope is exposed to the extracellular environment and becomes accessible to the SYT-lum antibodies without prior membrane permeabilization. However, the cytoplasmic epitope remains inaccessible to the SYTcyto antibodies in live neurons unless cell permeabilization is performed. In the present study, eye cup preparations containing the retina, $\mathrm{ONH}$, and a portion of the optic nerve were used to study potential vesicle exocytosis at the $\mathrm{ONH}$ following $\mathrm{LIOH}$. In control experiments using detergent-permeabilized frozen sections through the LIOH-treated ONH, both the SYT-lum and SYT-cyto antibodies exhibited patterns of ectopic accumulation similar to those for SV markers described above (data not shown). In studies of live retina/ optic nerve eye cups, tissue preparations were incubated at $37^{\circ} \mathrm{C}$ in either normal ACSF, high $\mathrm{K}^{+} \mathrm{ACSF}, \mathrm{Ca} 2^{+}$-free, high $\mathrm{K}^{+}$ACSF, or hypertonic sucrose ACSF. The live tissue preparations were then labeled with either SYT-lum or SYT-cyto antibodies without permeabilization to detect any exposed lumenal and cytoplasmic epitopes, followed by processing for cryosectioning. The bound synaptotagmin antibodies were detected with cy3-conjugated secondary antibodies without detergent permeabilization of the cryosections.

Following incubation in high $\mathrm{K}^{+}$ACSF to cause membrane depolarization and to stimulate exocytosis, SYT-cyto antibodies exhibited minimal staining at the $\mathrm{ONH}$ either in control (Fig. 4C) or LIOH-treated (Fig. 4D) retina/optic nerve preparations, except for occasional nonspecific blood vessel labeling (open arrowheads). These control conditions confirmed the specificity of SYT-cyto antibodies to the cytoplasmic domain of synaptotagmin, integrity of the live tissues, and absence of antibody diffusion into the cut end of optic nerves. In the presence of high $\mathrm{K}^{+}$, SYT-lum labeling at the control ONH was similarly minimal (Fig. 


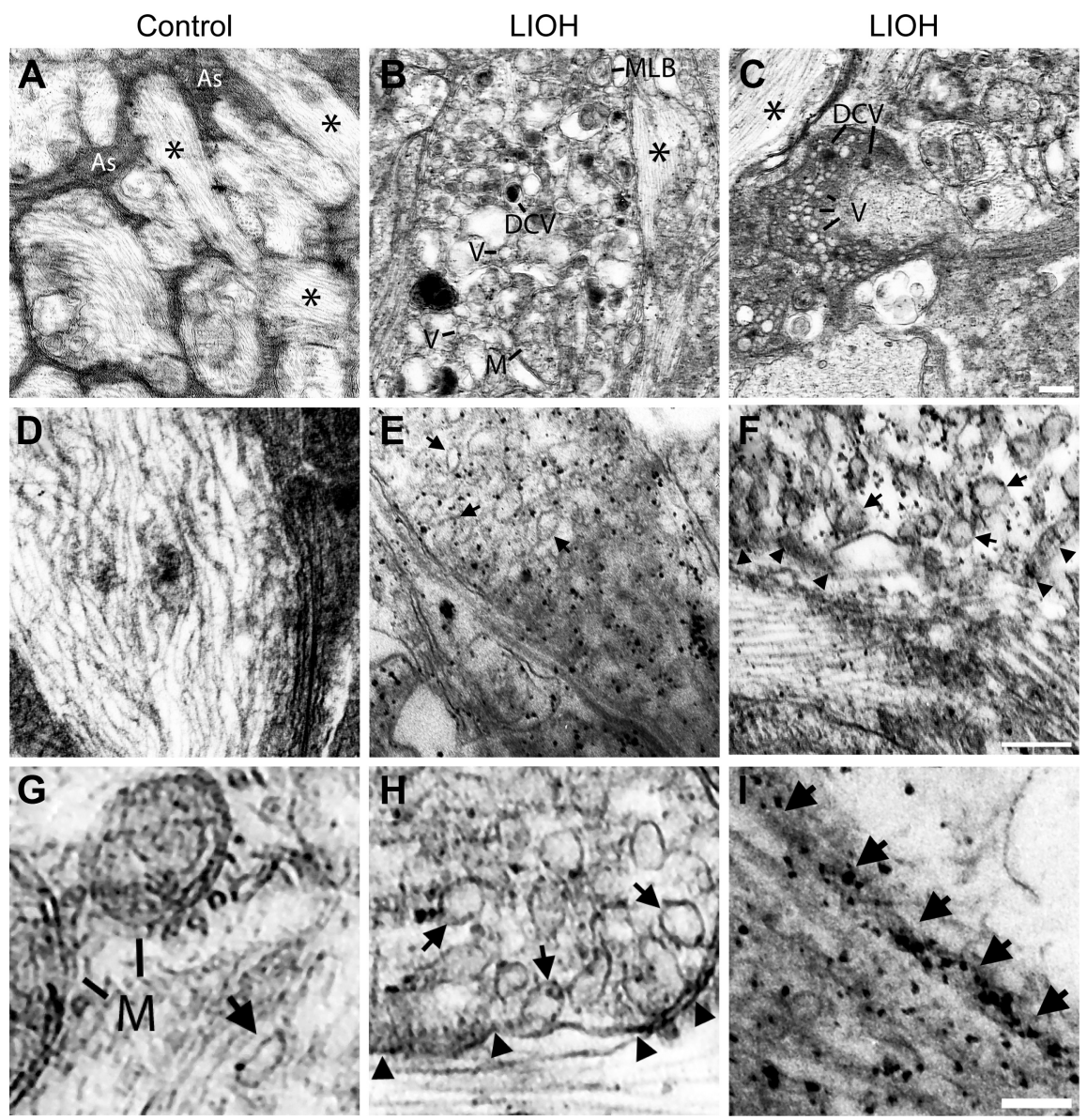

Figure 3. Ultrastructural analysis revealed the presence of synaptophysin-positive vesicles at the ONH after LIOH. ONH tissues harvested $2 \mathrm{~d}$ after $\mathrm{LIOH}$ were processed for electron microscopy along with control tissues. Antibodies directed against synaptophysin were used in postembedding immunogold labeling. $\boldsymbol{A}$, Control ONH. Unmyelinated RGC axon fibers (asterisks) are highly organized and in close association with astrocyte processes (As). B, C, LIOH ONH. Axon fibers were disorganized and often displayed swollen regions densely packed with membrane-bound organelles, including mitochondria (M), multilamellar bodies (MLB), translucent vesicles $(\mathrm{V})$, and dense core vesicles (DCV). The translucent vesicles were sometimes scattered among other organelles $(\boldsymbol{B})$ and sometimes aggregated in close apposition to the axolemma ( $\boldsymbol{C}$. Asterisks indicate neighboring axons that appeared similar to the normal axons in control ONH tissues. $D$-I, Medium- and high-magnification electron micrographs to visualize immunogold labeling. $\boldsymbol{D}$, Only sparse gold particle labeling was seen in the control. $\boldsymbol{E}, \boldsymbol{F}$, Intense labeling over translucent vesicle clusters (arrows) in $\mathrm{LIOH}$. Arrowheads in $\boldsymbol{F}$ point to electron-dense areas in association with the vesicles. $\boldsymbol{G}$, Vesicles were occasionally observed in control axons (arrow). $\boldsymbol{H}$, Another example of synaptophysin-positive vesicles (arrows), demonstrating electron-dense regions (arrowheads) along the abutting axolemma. $I$, Immunogold staining along the axolemma of one axon (arrows). Scale bars: (in C) $\boldsymbol{A}-\boldsymbol{C}, 300 \mathrm{~nm}$; (in F) D-F, $200 \mathrm{~nm}$; (in I) G-I, $100 \mathrm{~nm}$.

$4 A$ ), indicating a lack of exocytosis and exposure of the SYT lumenal epitope. In contrast, an increase of SYT-lum antibody staining was observed at $\mathrm{LIOH}$-treated ONHs under identical high $\mathrm{K}^{+}$conditions (Fig. $4 B$ ), indicating that the synaptotagmin lumenal epitope was exposed on the plasma membrane by vesicular fusion and was available for antibody binding. For data quantification (Fig. 4E,F), the measured fluorescence intensity in each condition was normalized against the SYT-cyto sample in the same experiment, so that results across different days could be compared. Of note, we found that the unstimulated LIOH ONH (Fig. $4 F$ ) also exhibited significant SYT-lum labeling above the level found in control tissues, suggesting that some exocytic events occurred in vivo in these experimental animals. However, the level of SYT-lum staining in unstimulated LIOH eye cup preparations was lower than that of that in $\mathrm{K}^{+}$stimulated preparations (Fig. 3, compare $E, F$ ).

We next investigated the effect of hypertonic sucrose stimulation, which induces the fusion of the readily releasable pool of synaptic vesicles (Rosenmund and Stevens, 1996; Kashani et al., 2001; Turner, 2004; Gerber et al., 2008). Sucrose stimulation resulted in higher SYT-lum staining than normal ACSF (Fig. 4G), suggesting that in addition to a basal level of exocytosis already occurring at the glaucomatous $\mathrm{ONH}$ in vivo, additional vesicles are competent for fusion in response to stimulation, in a way similar to the "docked" configuration of classical synaptic vesicles. The elimination of $\mathrm{Ca}^{2+}$ from the high $\mathrm{K}^{+}$ACSF reduced SYTlum labeling down to the unstimulated level, indicating that depolarizationevoked exocytosis was dependent on extracellular $\mathrm{Ca}^{2+}$.

In sum, these results indicated that at least a portion of the ectopic vesicles present at the $\mathrm{ONH}$ after $\mathrm{LIOH}$ treatment were competent for release following $\mathrm{K}^{+}$ or hypertonic sucrose stimulation ex vivo. Furthermore, the elevated SYT-lum staining found at the unstimulated $\mathrm{ONH}$ of $\mathrm{LIOH}$-treated animals suggested that vesicle exocytosis from axon segments at the $\mathrm{ONH}$ occurred in vivo in this animal model.

\section{Colocalization of glutamate with ectopic vesicles}

Glutamate is the excitatory neurotransmitter mediating transmission from RGCs (Shen et al., 2006). To investigate whether vesicles observed in RGC axons at the glaucomatous $\mathrm{ONH}$ contained glutamate like their normal counterparts, immunohistochemistry was performed on frozen eye cup/ONH tissue sections using a polyclonal antibody against glutamate. Control ONH sections exhibited only weak and diffuse staining (Fig. 5A), while LIOH-treated $\mathrm{ONH}$ sections showed increased immunoreactivity (Fig. $5 D$ ). Colocalization studies using SV2 as a marker for ectopic $\mathrm{ONH}$ vesicles demonstrated that glutamate and SV2 were extensively codistributed (Fig. 5F). At higher magnification, glutamate immunoreactivity, similar to that for SV2, was not evenly distributed within RGC axons, but was instead concentrated in discrete hot spots (Fig. $5 F$, inset). Of note, glutamate-positive (glutamate $^{+}$) hot spots were often slightly larger than the corresponding SV2 ${ }^{+}$hot spots (Fig. $5 F$, arrowheads). In addition, there were also glutamate immunoreactive regions that were not labeled with SV2 (Fig. 5F, double arrow). These observations suggested that glutamate was not confined only to the SV2 ${ }^{+}$vesicle-like structures.

\section{Glutamate release from the glaucomatous $\mathrm{ONH}$}

To investigate whether glutamate can be released from the $\mathrm{LIOH}$ $\mathrm{ONH}$, we used an enzymatic assay in which endogenous glutamate released from living tissues is visualized with NADH fluorescence imaging. GDH supplied in the assay solution converts glutamate to $\alpha$-ketoglutarate, concomitantly reducing $\mathrm{NAD}^{+}$to 

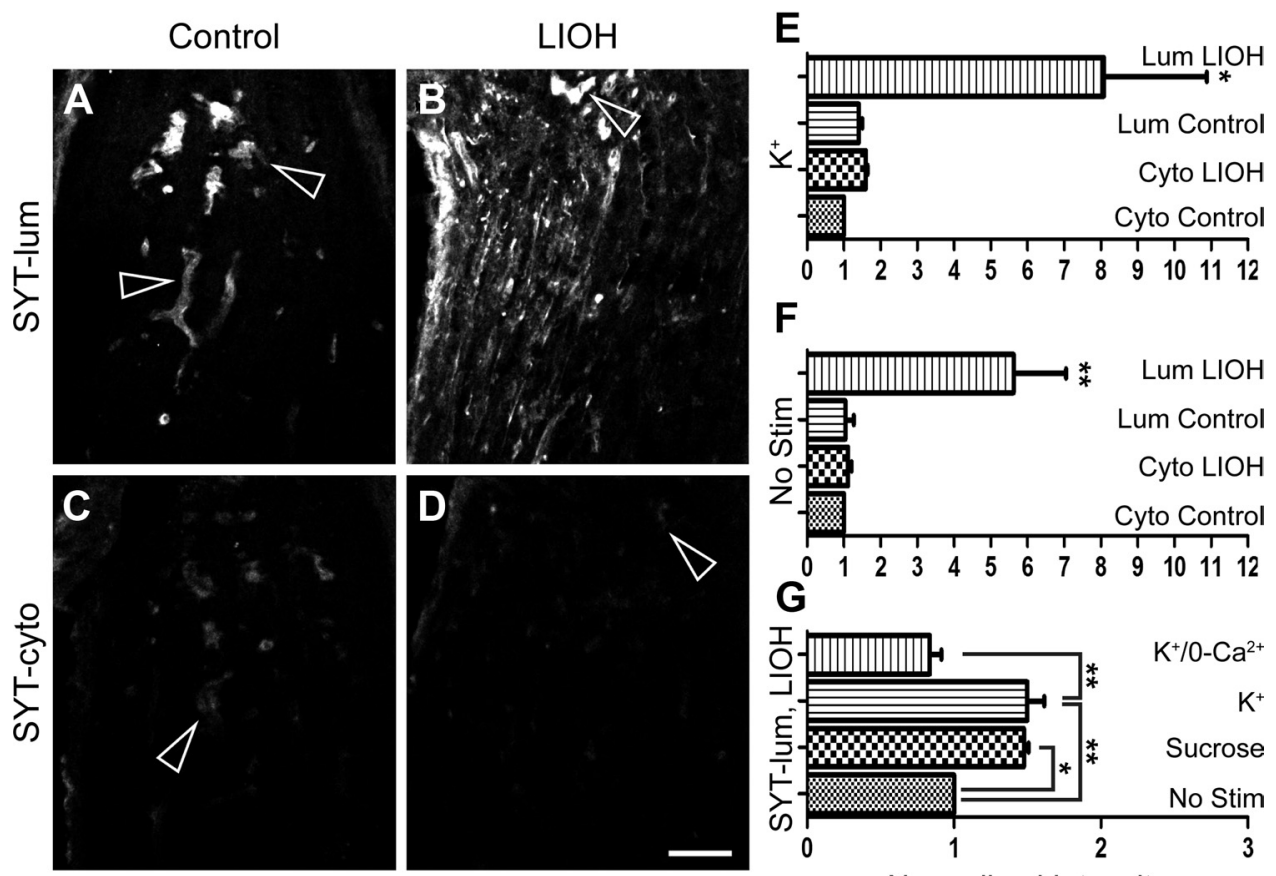

\section{$\mathbf{F}$}

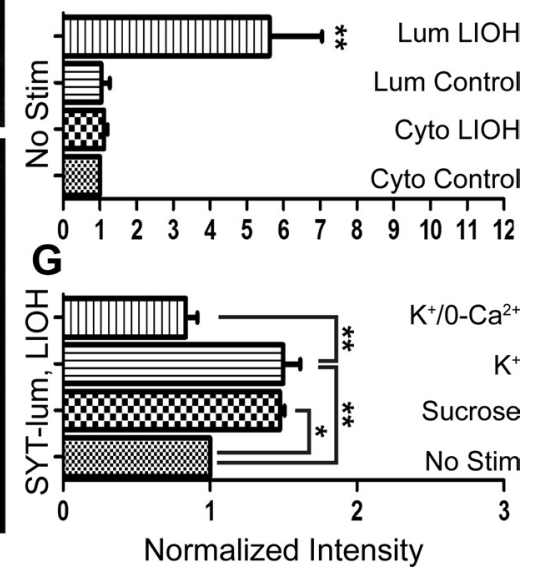

Figure 4. The labeling of live eye cups/ONH tissues with synaptotagmin lumenal domain antibodies demonstrated exocytosis of ectopic vesicles. Freshly dissected eye cups were incubated with antibodies against either SYT-lum or SYT-cyto as a negative control. $\boldsymbol{A}-\boldsymbol{D}$, A representative experiment in which tissues were stimulated with high $\mathrm{K}^{+}$before labeling. $\boldsymbol{C}, \boldsymbol{D}$, SYT-cyto produced no appreciable signal other than nonspecific blood vessel staining (open arrowheads). SYT-lum labeling was very weak in the control condition $(\boldsymbol{A})$, but increased markedly after LIOH (B), which appeared clearly distinguishable from the nonspecific staining (open arrowheads). $\boldsymbol{E}, \boldsymbol{F}$, Quantification of $\mathrm{K}^{+}$-stimulated $(\boldsymbol{E})$ and unstimulated $(\boldsymbol{F})$ experiments demonstrated significant upregulation of SYT-lum labeling at the LIOH ONHs compared to untreated controls. The analysis in $\mathbf{G}$ compared different SYT-lum labeling conditions for LIOH samples. The results were normalized against the unstimulated condition. Both high $\mathrm{K}^{+}$and hypertonic sucrose stimulation led to more substantial SYT-lum staining than normal $\mathrm{ACSF}$ alone. The elimination of $\mathrm{Ca}^{2+}$ from the high $\mathrm{K}^{+}$solution abolished the difference between stimulated and unstimulated conditions. Scale bar: (in D) $\boldsymbol{A}-\boldsymbol{D}, 50 \mu \mathrm{m} . \boldsymbol{E}, n=3$ experiments; $\boldsymbol{F}, n=4$ experiments; $\boldsymbol{G}, n=3$ experiments. ${ }^{*} p<0.05 ;{ }^{* *} p<$ 0.01. Before the experiments used for quantification, pilot studies with high $\mathrm{K}^{+} \mathrm{ACSF}$ were conducted six times with similar results.

$\mathrm{NADH}$, which fluoresces under UV excitation (Ayoub et al., 1998; Ayoub and Dorst, 1998; Maguire et al., 1998; Innocenti et al., 2000).

Freshly dissected control or LIOH ONH tissue was incubated with an enzymatic assay solution containing GDH and $\mathrm{NAD}^{+}$. Stimulation was introduced by either high $\mathrm{K}^{+}$or hypertonic sucrose, and the release of glutamate was monitored by detecting $\mathrm{NADH}$ accumulation with time-lapse fluorescence imaging. Figure 5, $G$ and $H$, shows a pseudocolored representative experiment with sucrose. In the control ONH (Fig. 5G), application of sucrose produced no detectable change in $\mathrm{NADH}$ fluorescence over time. In contrast, sucrose stimulation of the LIOH ONH led to marked enhancement of NADH fluorescence (Fig. $5 \mathrm{H}, \mathrm{J}$ ), indicating glutamate release within the tissue sample. The application of high $\mathrm{K}^{+}$also caused a significant rise of NADH fluorescence in $\mathrm{LIOH}$-treated but not in control ONH tissues (Fig. 5I).

\section{Glutamate receptor expression on RGC axons and glia at the $\mathrm{ONH}$}

To examine whether regulated glutamate release from $\mathrm{ONH}$ axons following LIOH may have potential functional significance, we first performed glutamate receptor immunolocalization studies using subunit-specific antibodies. The results showed that the AMPA receptor subunit GluR1 was expressed in a punctate pattern throughout the normal ONH (Fig. 6A). After LIOH, GluR1 immunoreactivity became more heterogeneous, with intensely labeled axonal segments (Fig. 6B, arrows) meandering through more uniformly stained patches. The GluR2 subunit exhibited a similar expression pattern (data not shown). NMDA receptor subunit NR1 immunoreactivity was found at a low level in the control ONH (Fig. 6C). After LIOH treatment, the ONH expression of NR1 was strongly upregulated (Fig. 6D).

The increased expression of NR1 following LIOIH was corroborated with immunodot blotting using an anti-NR1 antibody (Brose et al., 1994; Siegel et al., 1994; Carlton et al., 1995; Coggeshall and Carlton, 1998; Iwasato et al., 2000; Milner and Drake, 2001; South et al., 2003). In conventional Western blots using mouse brain and retinal tissues, this antibody detected a band of the predicted size (120 kDa) (Data not shown). In dot blotting experiments, each sample contained protein extracts pooled from $10 \mathrm{ONHs}$, as explained in Figure 1. Analysis of NR1 levels corrected against the GAPDH loading control revealed a threefold increase $(p=0.04)$ of expression after LIOH (Fig. $6 E$ ).

Colabeling experiments were performed to examine the cellular localization of glutamate receptors. GluR1 was colocalized with neuron-specific tubulin $\beta$-III (Fig. $6 H$ ), GFAP $(K)$, and CD11b $(N)$, suggesting widespread GluR1 expression on RGC axons, astrocytes, and microglia. NR1 immunoreactivity exhibited a similar pattern of cellular distribution on RGC axons and astrocytes.

\section{Functional demonstration of $\mathrm{ONH}$ glutamate receptor activity}

AGB was used to provide evidence of ionotropic glutamate receptor activation within the $\mathrm{LIOH}$-treated $\mathrm{ONH}$. The activation of ionotropic glutamate receptors in the presence of the channelpermeant organic cation AGB results in AGB entry intracellularly, after which AGB can be trapped by glutaraldehyde fixation and detected with specific antibodies (Marc, 1999b; Marc et al., 2005). AGB has been used to functionally map ionotropic gluta- 


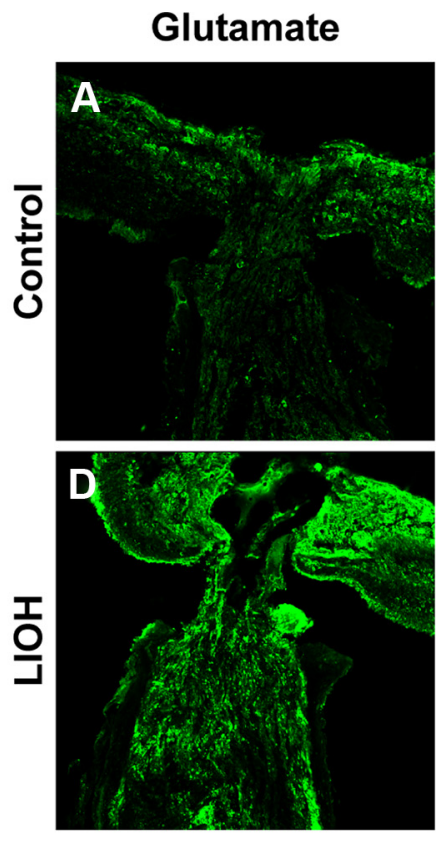

G

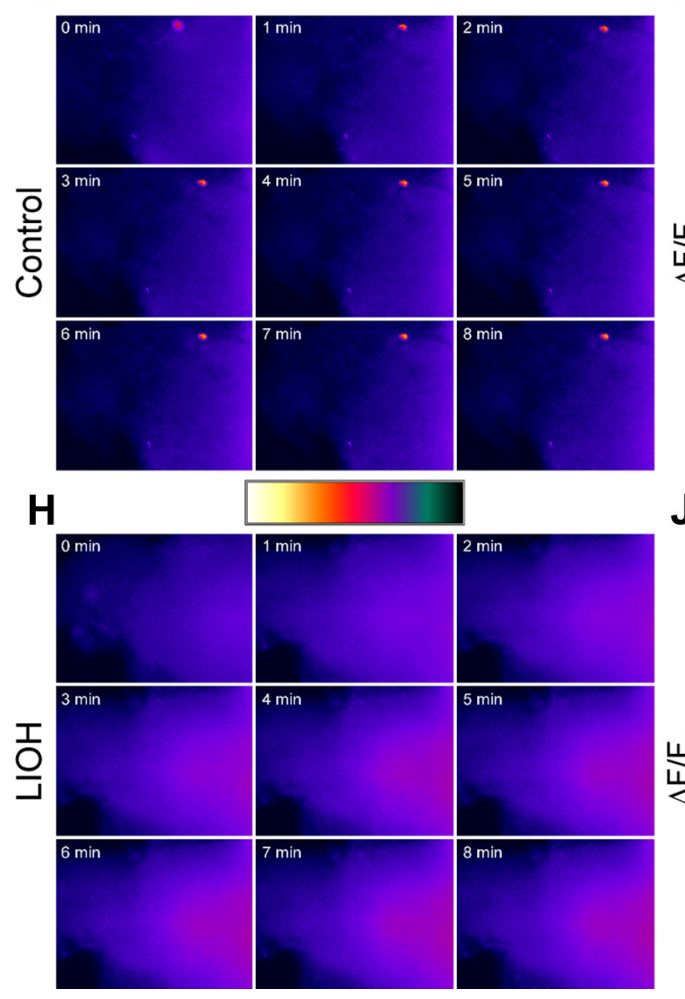

SV2
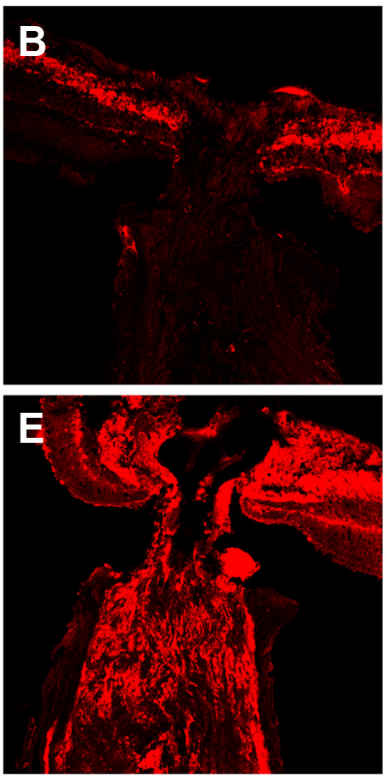

I
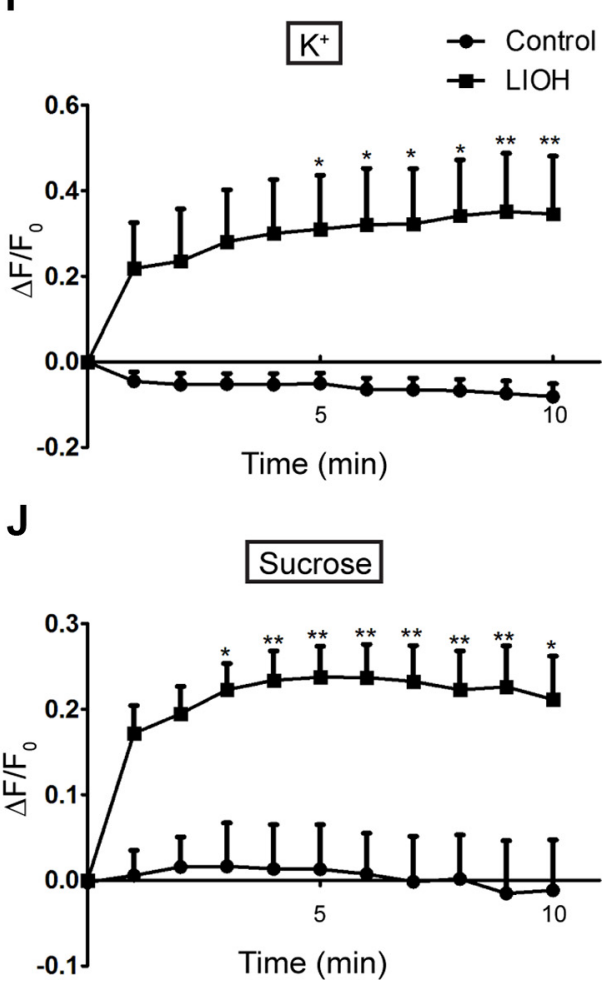

Figure 5. $\quad \boldsymbol{A}-\boldsymbol{F}$, Immunodetection of glutamate at the $\mathrm{ONH}$. In control samples, glutamate $(\boldsymbol{A})$ and $\mathrm{SV} 2(\boldsymbol{B})$ patterns of immunoreactivity were similarly weak and diffuse. LIOH treatment resulted in dramatic $0 \mathrm{NH}$ accumulation of both glutamate $(\boldsymbol{D})$ and SV2 $(\boldsymbol{E})$, which were colocalized extensively $(\boldsymbol{F})$. The high-magnification inset taken from the boxed region demonstrates that glutamate and SV2 were found in hot spots along the RGC axons. Although a few of these hot spots were only labeled with SV2 (arrow) or glutamate (double arrow), in most instances the two markers overlapped, with the glutamate hot spots being slightly larger (arrowheads). $n>13$ pairs of eyes. A LIOH day 4 sample is shown here. Scale bar: (in $F$ ) $\boldsymbol{A}-\boldsymbol{F}, 50 \mu \mathrm{m}$. G-J,NADH assay detected release of glutamate from acutely prepared $\mathrm{LIOH} \mathrm{ONH}$ tissues. $\mathbf{G}, \boldsymbol{H}$, A representative time-lapse experiment in which hypertonic sucrose was introduced to provide stimulation. No change in fluorescence level was detected in the control ONH $(\boldsymbol{G})$. In the LIOH ONH $(\boldsymbol{H})$, a robust rise in NADH fluorescence resulted from sucrose stimulation, as visualized by the pseudocolored montage. Images captured at 1 min intervals are shown. Quantification of fluorescence intensity shows that both high $\mathrm{K}^{+}(I)$ and hypertonic sucrose $(J)$ stimulation resulted in significant accumulation of NADH in the $\mathrm{LIOH}$ $0 \mathrm{NH}$, suggesting that glutamate was released from the tissue. $n=6$ for both control and $\mathrm{LIOH}$ in $I . \operatorname{In} J, n=9$ for control and 19 for LIOH. ${ }^{*} p<0.05 ;{ }^{* *} p<0.01$.

mate receptors in developing and adult retinas of several mammalian species (Marc, 1999a,b; Kalloniatis et al., 2002, 2004; Sun et al., 2003, 2007a,b; Rohrer et al., 2004; Sun and Kalloniatis, 2004, 2006; Marc et al., 2005; Acosta et al., 2007, 2008; Chang and
Chiao, 2008). In the present study, AGB was injected into the subconjunctival space of anesthetized control or $\mathrm{LIOH}$ mice to allow for reagent access into the $\mathrm{ONH}$. Control experiments confirmed that there was no endogenous anti-AGB signal without 

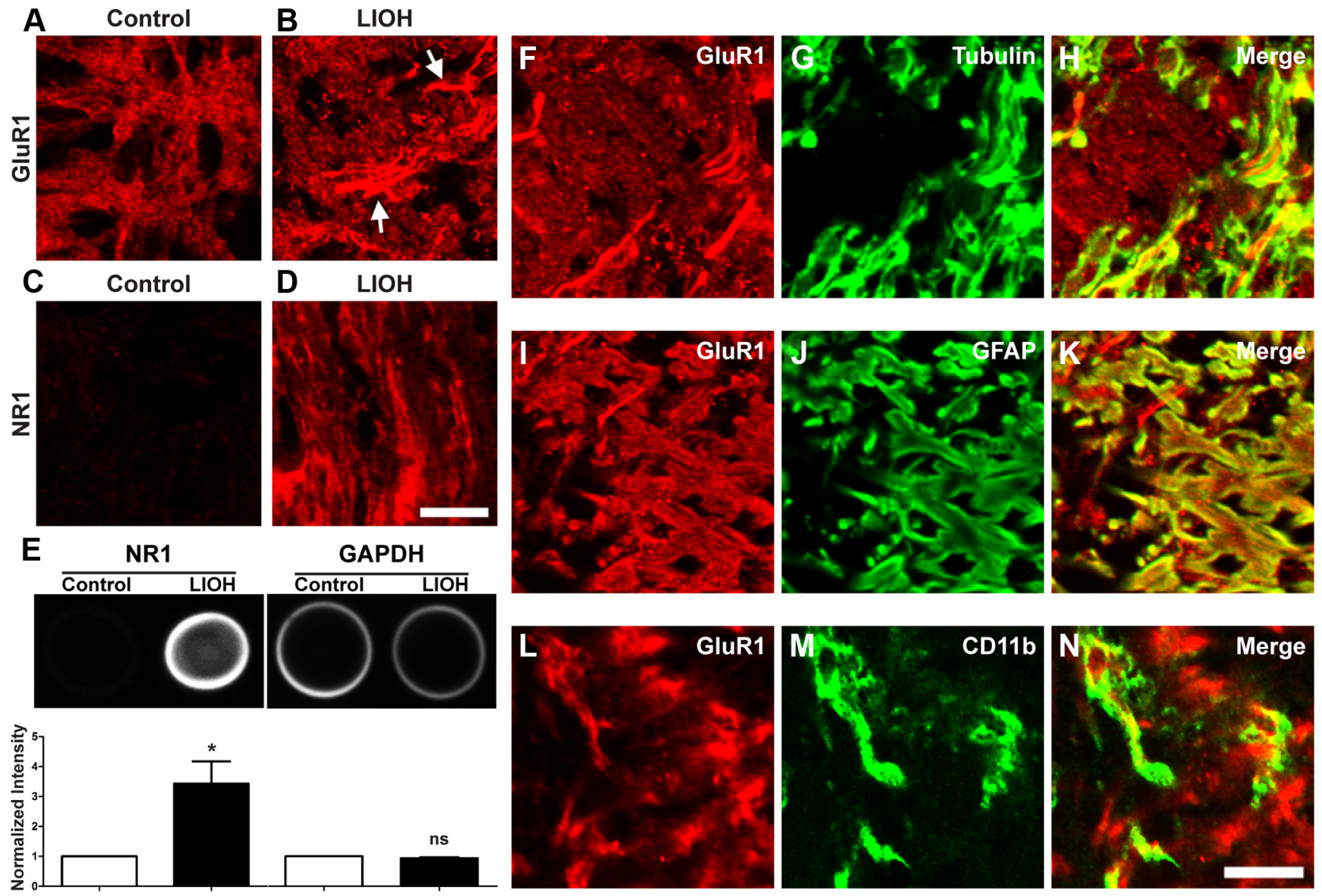

Figure 6. Expression of glutamate receptor subunits on RGC axons and glia at the ONH. Images acquired from LIOH day 2 samples are shown. $\boldsymbol{A}$, GluR1 expression at control ONH. $\boldsymbol{B}$, GluR1 expression after LIOH. Concentrated GluR1 expression was detected in abnormal axon segments (arrows). C, D, NR1 expression was low in the control ONH (C) but demonstrated strong upregulation following $\mathrm{LIOH}(\boldsymbol{D})$. E, Dot blot analysis of NR1 expression in ONH samples using GAPDH as a loading control confirmed the upregulation of NR1 $2 \mathrm{~d}$ after LIOH. Three pairs of control and LIOH-treated samples containing $100 \mathrm{NHs}$ each were analyzed. ${ }^{*} p<0.05$. $\boldsymbol{F}-\boldsymbol{N}$, Colabeling studies of GluR1 $(\boldsymbol{F}, \boldsymbol{I}, \boldsymbol{L})$ with tubulin $(\boldsymbol{G}), \mathrm{GFAP}(\boldsymbol{J})$, and $\mathrm{CD} 11 \mathrm{~b}(\boldsymbol{M})$ demonstrated that GluR1 was expressed on axons $(\boldsymbol{H})$, astrocytes $(\boldsymbol{K})$, and microglia $(\boldsymbol{N})$. Scale bars: $\boldsymbol{D}$ (for $\boldsymbol{A}-\boldsymbol{D}), \boldsymbol{N}($ for $\boldsymbol{F}-\boldsymbol{N}) 50 \mu \mathrm{m}$.

application of AGB (data not shown), in agreement with previous reports (Marc, 1999a,b; Kalloniatis et al., 2002). Control mice injected with AGB exhibited only low levels of punctate labeling at the $\mathrm{ONH}$ (Fig. $7 A$ ). In contrast, AGB signal at the $\mathrm{ONH}$ of LIOH-treated animals was noticeably increased (Fig. 7D), a finding confirmed quantitatively (Fig. 7G). AGB immunoreactivity colocalized with tubulin $\beta$-III (Fig. $7 E, F$ ), suggesting that ionotropic receptors were endogenously activated on $\mathrm{ONH}$ axons following $\mathrm{LIOH}$ induction. AGB immunoreactivity was also detected in a diffuse punctate manner in astrocytes identified by colabeling with GFAP (data not shown). These findings indicate that the ONH glutamate receptor subunits observed in this study were likely functionally active.

Pharmacological blockade of glutamate signaling attenuated LIOH-induced axon degeneration in vivo

To examine the potential in vivo effects of glutamate receptor activation in axons and glia at the $\mathrm{LIOH}$-induced glaucomatous $\mathrm{ONH}$, we surgically implanted gel foam plugs soaked with an NBQX/MK-801/TTX mixture next to the ONH $1 \mathrm{~d}$ after LIOH induction. NBQX and MK-801 block ionotropic AMPA/kainate and NMDA glutamate receptors, respectively. The voltagegated sodium channel blocker TTX dampens the excitability of axons, which would presumably result in lower glutamate release. Optic nerves were harvested $6 \mathrm{~d}$ after gel foam implantation, and the axon numbers were quantified in PPD-stained tissue cross-sections. PPD histochemistry has been used extensively to analyze glaucomatous axonal degeneration in optic nerves (Davies et al., 1995; Libby et al., 2005a; Zhong et al., 2007) and labels healthy myelinated axons uniformly, but gives rise to distinct dark staining over the axoplasm of degenerating axons (Libby et al., 2005a). In the current set of experiments, IOP elevation induced by LIOH was comparable in both treatment conditions, indicating that the NBQX/MK-801/ TTX drug application did not affect aqueous humor production or drainage (Fig. 8 E). Examination of PPD-stained optic nerve sections from LIOH animals without pharmacological blockade revealed prominent axonal degenerative debris marked by darkly stained axoplasm, (Fig. 8C, arrowhead) and axonal swelling (Fig. 8C, arrow). This morphological damage was also present but to a more moderate extent in the drug-treated group (Fig. $8 D$ ). The quantitative scoring of PPD-stained myelinated axons indicated that the number of surviving axons was significantly higher in the antagonist mixturetreated group compared to vehicle-treated animals (Fig. $8 F$ ). Of note, we also observed that optic nerves treated with the antagonist mixture exhibited less pronounced gliosis (Fig. $8 B$ ) compared to optic nerves subjected to vehicle alone (Fig. $8 A$ ). These data demonstrated that the pharmacological blockade of glutamate signaling resulted in a moderation of axon loss in experimental glaucoma. 

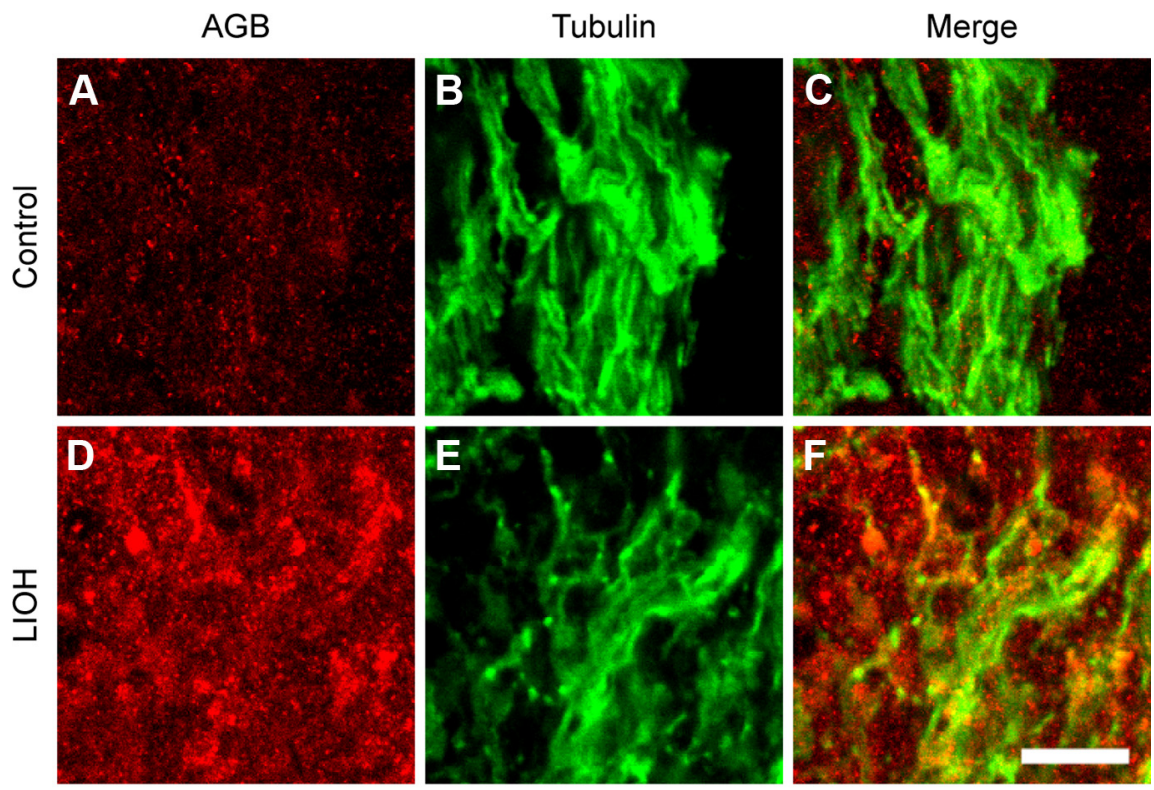

G

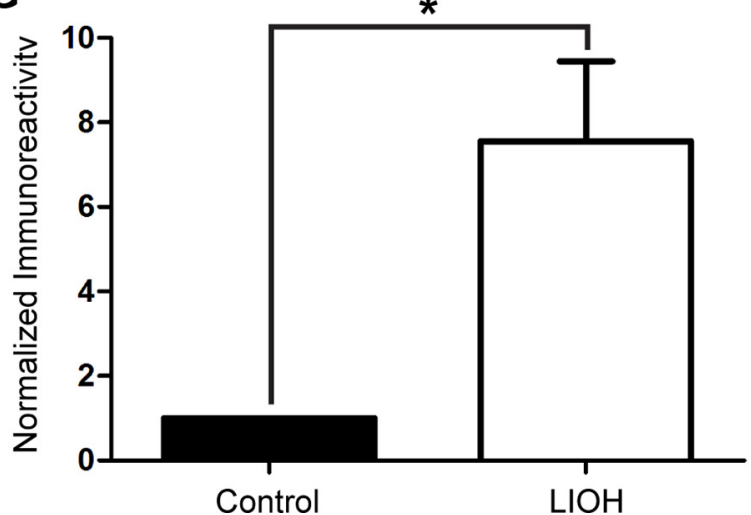

Figure 7. Demonstration of ionotropic glutamate receptor activation using the channel-permeant organic cation $A G B$. $A, D$ After exposure to $A G B$ in vivo through subconjunctival injection, control $(\boldsymbol{A})$ and $\mathrm{LIOH}(\boldsymbol{D})$ tissues were labeled with antibodies directed against AGB. $\boldsymbol{B}, \boldsymbol{E}$, Colabeling with tubulin was performed. $\boldsymbol{C}, \boldsymbol{F}, \mathrm{AGB}$ immunostaining was found to overlap with tubulin at the ONH. G, Quantitative studies show that AGB immunoreactivity was significantly higher in LIOH compared to control ONHs. Scale bar: (in $\boldsymbol{F}) \boldsymbol{A}-\boldsymbol{F}, 50 \mu \mathrm{m} . n=4$ experiments. ${ }^{*} p<0.05$.

\section{Generation of albino mice carrying floxed alleles of VGLUT2 and NR1}

The data so far have supported a model in which ectopic accumulation of SV protein-containing vesicles at the glaucomatous ONH led to ectopic exocytotic glutamate release that contributed to the degeneration of RGC axons. Although the in vivo pharmacological antagonism experiments provide a supporting line of evidence, drug application does not address which cell type is the primary target of glutamate action, as glutamate may directly bind to its receptors on RGC axons or participate in axonal degeneration indirectly through glial activation. To provide additional tests of the role of glutamate signaling in $\mathrm{LIOH}$-induced axon loss, and to gain further mechanistic insight, we examined LIOH-treated transgenic mice in which key components of the proposed pathophysiological pathway were genetically deleted specifically in RGCs. Two transgenic lines were used: one that carries the floxed Slc17a6 gene, which encodes VGLUT2 (Hnasko et al., 2010), and one that carries the floxed NR1 gene (Tsien et al., 1996). Cre recombinase was delivered by intravitreal injection of rAAV that transduces RGC with high efficiency and specificity (Cheng et al., 2002; Martin et al., 2002; Malik et al., 2005; Park et al., 2008; Hellstrom et al., 2009; Ivanova and Pan, 2009; Pease et al., 2009).

The floxed Slc17a6 (VGLUT2-f) and floxed NMDAR1 (NR1-f) mice, both of which were originally maintained in the C57BL/6 background, were crossed to a coisogenic strain B6(Cg)-Tyr ${ }^{c-2 J} / \mathrm{J}$ (The Jackson Laboratory) of albino mice homozygous for a $\mathrm{Tyr}^{\mathrm{c}-2 J}$ mutation in the tyrosinase gene to circumvent the problem of $\mathrm{LIOH}$ induction in pigmented mouse strains (see Materials and Methods). The pigmented floxed mice were crossed with B6 albino mice for two generations to produce albino VGLUT2-f (Slc17a $6^{\text {loxP/loxP }}$; $\left.T y r^{c-2 J / c-2 J}\right)$ and albino NR-f (NR1 $1^{\text {loxP/loxP }}$; $\left.T y r^{c-2 J / c-2 J}\right)$ mice, which were then used in subsequent LIOH studies.

\section{Intravitreal injection of recombinant AAV vectors}

An AAV vector carrying the Cre recombinase (AAV-Cre) was used to conditionally delete floxed genes encoding VGLUT2 or NR1. An AAV vector for GFP expression (AAV-GFP) was used as a control. The vectors were generously provided by Dr. Z. He and have been described previously (Park et al., 2008). Using the reporter line Rosa26-EYFP Ai3 (Madisen et al., 2010) and NeuN as a marker for RGCs (Buckingham et al., 2008), we found that Cre recombination occurred in $\sim 90 \%$ of the total RGCs identified in flat-mounted retinas 3 weeks after intravitreal injection of AAV-Cre (data not shown). This finding agrees with those of Park et al. (2008), who reported $>90 \%$ transduction efficiency 2 weeks following intravitreal injection. In the optic nerve, RGC axons were the only cellular elements transduced.

\section{VGLUT2 deletion in RGCs diminished glutamate accumulation at the LIOH-treated ONH}

Albino VGLUT2-f mice were injected intravitreally with AAVCre in one eye and AAV-GFP in the fellow eye followed 3 weeks later by $\mathrm{LIOH}$ treatment. Similar to the CD-1 mice reported above, AAV-GFP-injected B6 albino mice exhibited accumulation of VGLUT2 immunoreactivity at the LIOH ONH (Fig. 9A), which colocalized with the axon marker tubulin $\beta$-III (Fig. 9C). AAV-Cre injection resulted in effective knockdown of VGLUT2 accumulation. In some cases, VGLUT2 immunoreactivity at the ONH was nearly abrogated (Fig. 9D).

Accumulation of glutamate immunoreactivity was observed in AAV-GFP-injected VGLUT2-f mouse ONH after LIOH (Fig. $9 G$ ), and overlapped with that of SV2 extensively (Fig. 9I), consistent with the findings in CD-1 mice. Higher magnification (Fig. 9I, inset) revealed that glutamate immunoreactivity was heterogeneous and appeared in intensely labeled patches, closely associated with corresponding SV2 hot spots. In AAV-Creinjected $\mathrm{ONH}$, glutamate labeling after $\mathrm{LIOH}$ was markedly diminished (Fig. 9J). While SV2 accumulation remained (Fig. 9K), 
glutamate staining was weak and diffuse, and did not correlate with SV2 hot spots (Fig. 9L, inset). Quantitative analysis confirmed that the observed reduction in VGLUT2 (Fig. 9S) and glutamate (Fig. 9T) immunoreactivity by AAV-Cre was statistically significant. These findings confirmed that the conditional gene deletion was indeed specific and effective for downregulating VGLUT2 expression. Ectopic vesicles were still present at the $\mathrm{ONH}$, although most of them became devoid of VGLUT2 after AAV-Cre transduction, and presumably have lost the ability to accumulate glutamate.

\section{VGLUT2 deletion in RGCs attenuated glutamate receptor activity at the LIOH-treated ONH}

To further confirm the downregulation of glutamate signaling at the $\mathrm{ONH}$ of AAV-Cre-treated VGLUT2-f animals, ionotropic glutamate receptor activation was probed using AGB. In the AAV-GFP control condition, LIOHtreated B6 albino VGLUT2-f mice displayed strong AGB labeling at the $\mathrm{ONH}$ (Fig. 9M), which was present in both axons $(O)$ and glia (data not shown). After AAV-Cre injection, the overall level of receptor activation was attenuated (Fig. 9P), presumably as a consequence of the diminution of glutamate accumulation due to VGLUT2 knockdown. AGB immunoreactivity over RGC axons was quantified and found to be significantly reduced by $70 \%$ in AAV-Cre (Fig. 9U).

\section{Deletion of VGLUT2 in RGCs promoted axon survival in experimental glaucoma}

Axonal survival in AAV-Cre-injected VGLUT2-f mice after LIOH was investigated by analyzing PPD-stained optic nerve cross-sections. IOP elevation after $\mathrm{LIOH}$ treatment was similar in animals receiving AAV-GFP or AAV-Cre (Fig. $9 W)$. In B6 albino VGLUT2-f mice injected with the AAV-GFP control vector, $\mathrm{LIOH}$ resulted in notable axon dropout after 2 weeks (Fig. 9V). The overall level of damage was less severe than in aged-match CD-1 mice, but dark axonal degenerative debris could be readily observed. In AAV-Cre-injected VGLUT2-f mice, axonal disorganization and degeneration still occurred, but a higher proportion of axons appeared morphologically normal (Fig. 9V). Quantitative analysis showed that $\mathrm{LIOH}$ reduced RGC axon count to $55 \%$ of control level in the AAV-GFP injection group after 2 weeks. AAV-Cre-mediated deletion of VGLUT2 resulted in a significant restoration in the number of RGC axons (Fig. $9 X$ ) to $77 \%$ of control level $(p<0.01$ for AAV-Cre vs GFP). These data indicated that the interference with RGC vesicular glutamate release promoted axonal survival in $\mathrm{LIOH}$-induced experimental glaucoma. As axonal survival was not fully restored to the levels in
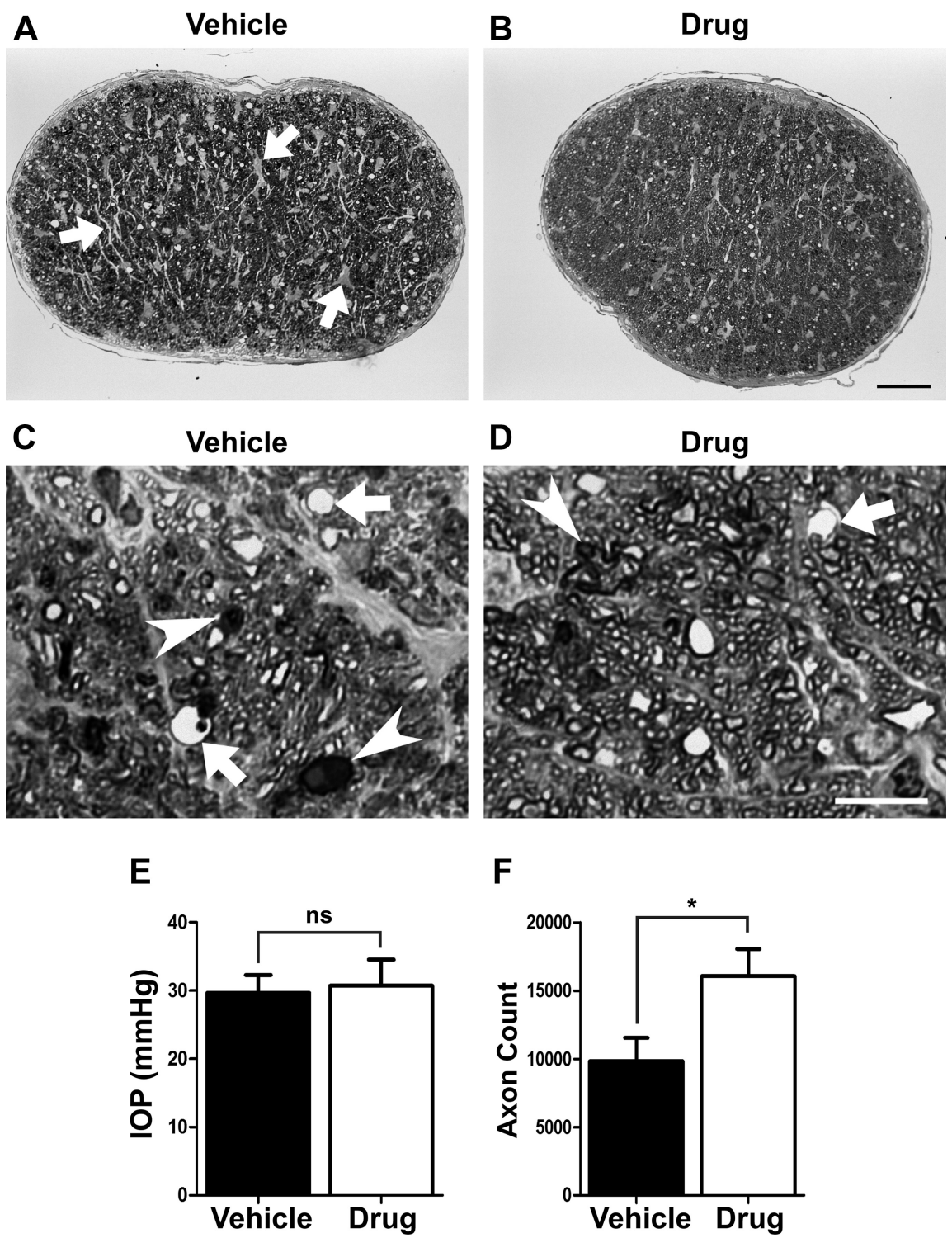

Figure 8. Effects of glutamate signaling antagonists on optic nerve axonal degeneration in vivo. A mixture of glutamate signaling antagonists, NBQX/MK-801/TTX, or vehicle was delivered locally to the ONH of animals treated with LIOH. Optic nerves were harvested and analyzed after 1 week. $\boldsymbol{A}, \boldsymbol{B}$, Example low-magnification cross-sectional images of PPD-stained optic nerve. (B). C, D, Example high-magnification images. Axonal degenerative debris (arrowheads) and axonal swelling (arrows) were more pronounced in the vehicle-treated group $(\boldsymbol{C})$ than the drug-treated group $(\boldsymbol{D})$. $\boldsymbol{E}$, IOP elevation in both groups was comparable. $\boldsymbol{F}$ The drug-treated group had significantly higher number of surviving axons in the optic nerve compared to vehicle-treated control. Scale bars: (in $\boldsymbol{B}) \boldsymbol{A}, \boldsymbol{B}, 50 \mu \mathrm{m}$; (in $\boldsymbol{D}) \boldsymbol{C}, \boldsymbol{D}, 10 \mu \mathrm{m} . n=11$ animals analyzed. ns, Not significant. ${ }^{*} p<0.05$.

control animals, vesicular glutamate release and localization excitotoxicity likely only account for one of the mechanisms of RGC axon loss in LIOH. In addition, other sources of glutamate release may contribute to the accumulation of $\mathrm{ONH}$ glutamate.

NR1 deletion in RGCs reduced axonal glutamate signaling at the $\mathrm{LIOH}$-treated $\mathrm{ONH}$ and promoted axon survival

To investigate the potential cellular targets of glutamate, we performed NR1 knockdown in RGCs using a similar AAV-Cre approach in NR1-f mice. Since NR1 is an essential subunit of the NMDA receptor (Moriyoshi et al., 1991; Nakanishi, 1992), disruption of NR1 in RGC axons should reduce the ability of glutamate to act on NMDA receptors on axons at the ONH. The AGB activation assay was used as a measure of NR1 knockdown. AGB 

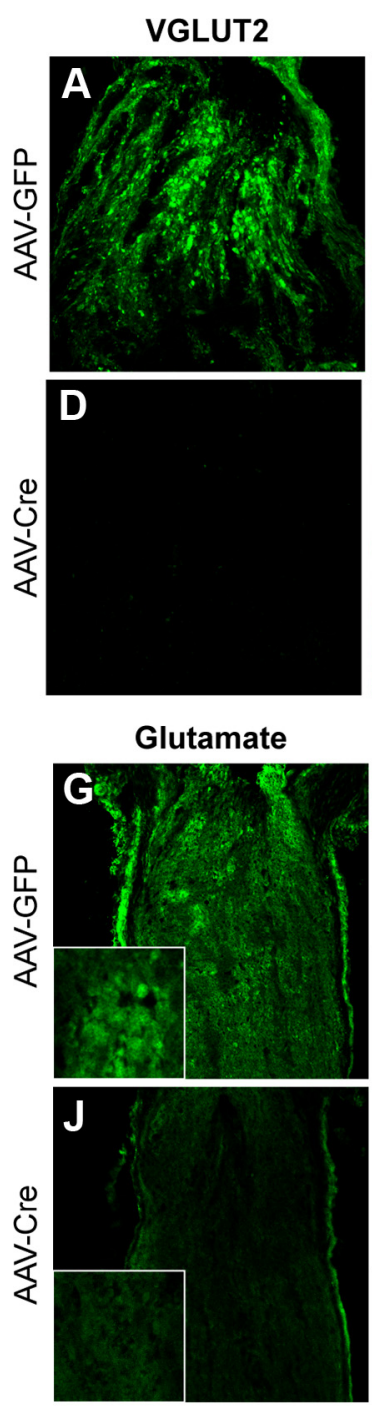

AGB
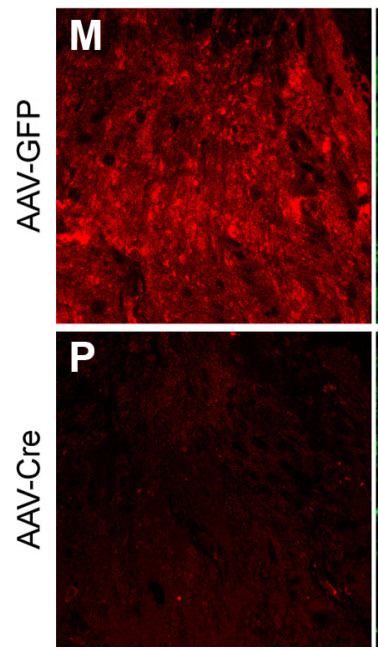

Tubulin
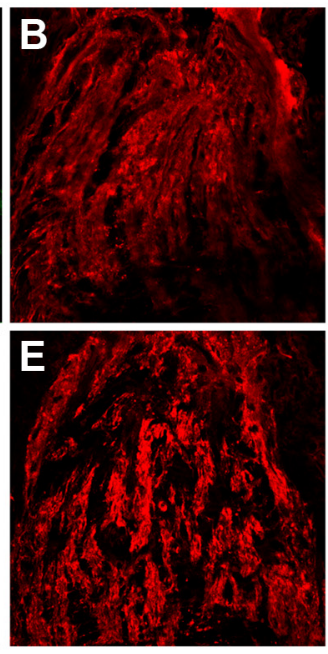

SV2
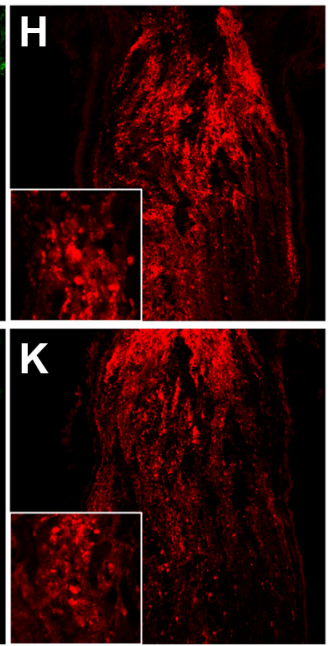

Tubulin
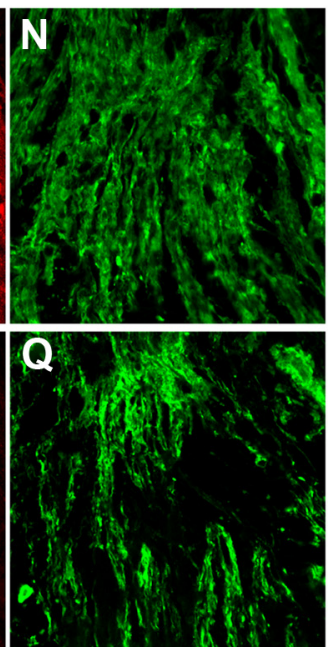
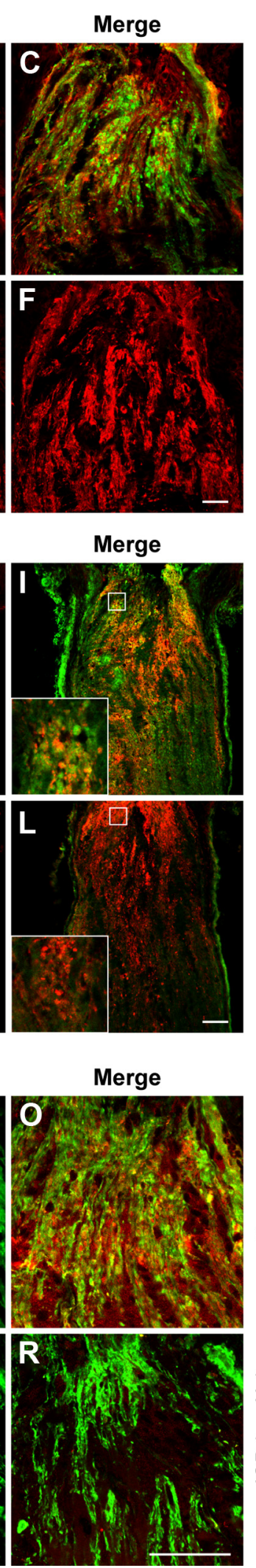
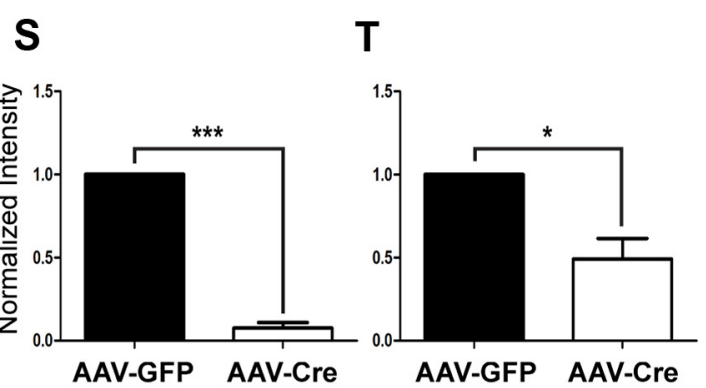

U

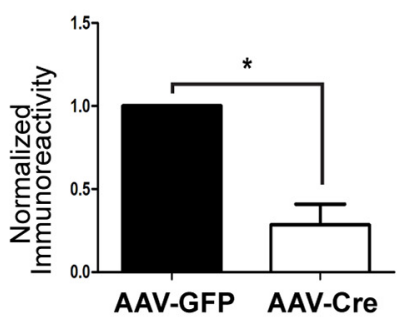

V
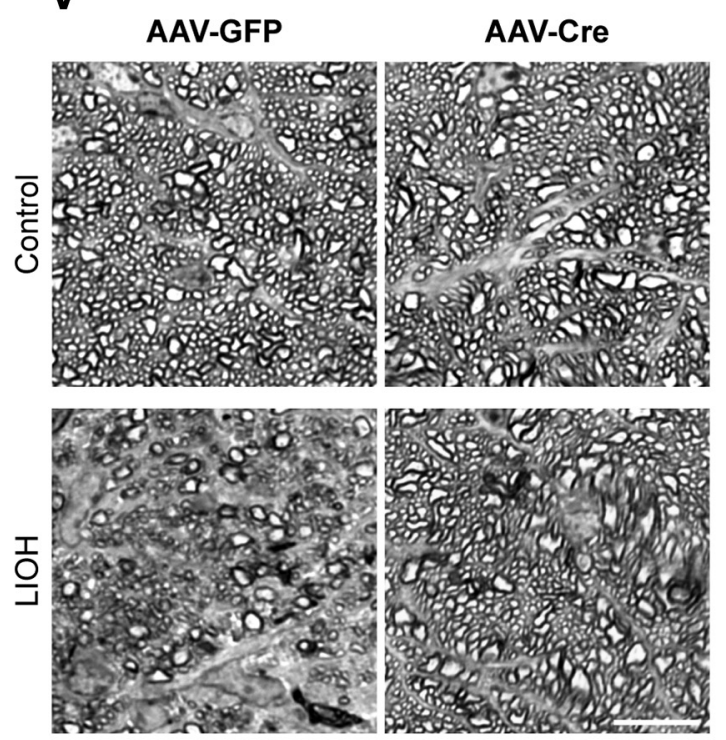

W
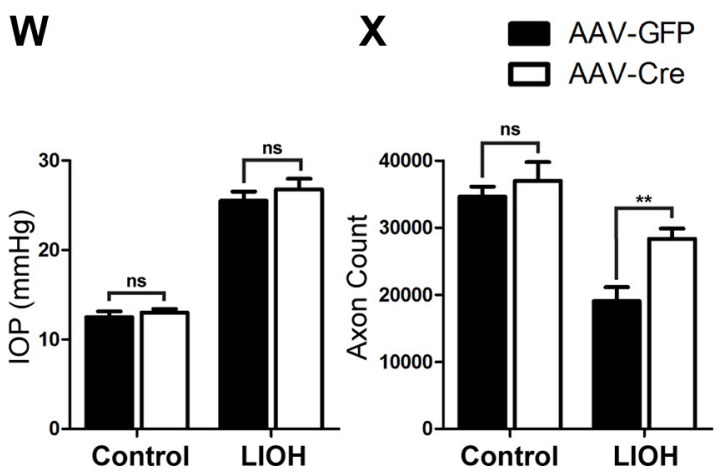

Figure 9. AAV-Cre-mediated deletion of VGLUT2 attenuated RGC axon loss after LIOH. $\boldsymbol{A}-\boldsymbol{F}$, Effective VGLUT2 knockdown by AAV-Cre in VGLUT2-f mice. The accumulation of VGLUT2 after LIOH (day 3) was observed in AAV-GFP-injected VGLUT2-f mouse ONH (A), but was almost abolished in the AAV-Cre-injected eye (D). Colabeling with $\beta$-III Tubulin $(\boldsymbol{B}, \boldsymbol{E})$ was used to detect the presence of VGLUT2 in RGC axons. G-L, Reduction of ONH glutamate by AAV-Cre in VGLUT2-f mice. SV2 labeling after LIOH (day 3) was not altered in AAV-Cre ( $\boldsymbol{K}$ ) compared to AAV-GFP ( $\boldsymbol{H})$, but glutamate immunoreactivity was much reduced in the AAV-Cre condition (compare $J, G$ ). Glutamate and SV2 hot spots often codistributed in the AAV-GFP control (G-I, insets taken from the boxed region in I). In AAV-Cre, glutamate labeling was more diffuse and no longer mirrored SV2 hot spots $(\boldsymbol{J}-\boldsymbol{L}$, insets taken from the boxed region in $\boldsymbol{L}$ ). $\boldsymbol{M}-\boldsymbol{R}$, AGB assay demonstrated reduced glutamate receptor activity by AAV-Cre injection in VGLUT-f mice. AGB injected subconjunctivally $3 \mathrm{~d}$ after LIOH resulted in strong AGB labeling $(\boldsymbol{M})$ at the ONH of the AAV-GFP group. $\beta$-III Tubulin staining ( $\boldsymbol{N}$ ) showed that part of the AGB signal was localized to axons $(\mathbf{0})$, although additional glial labeling was also present. AAV-Cre injection markedly reduced the overall level of AGB staining (Figure legend continues.) 


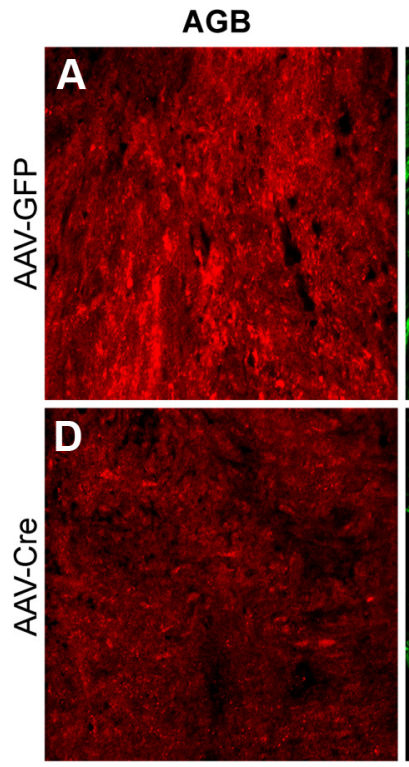

H
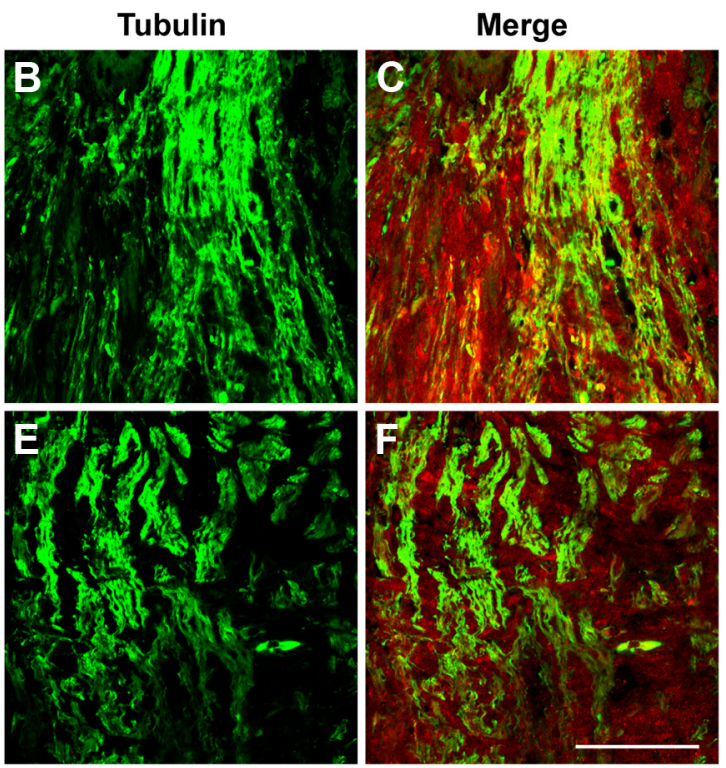

I

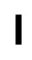

AAV-GFP AAV-Cre
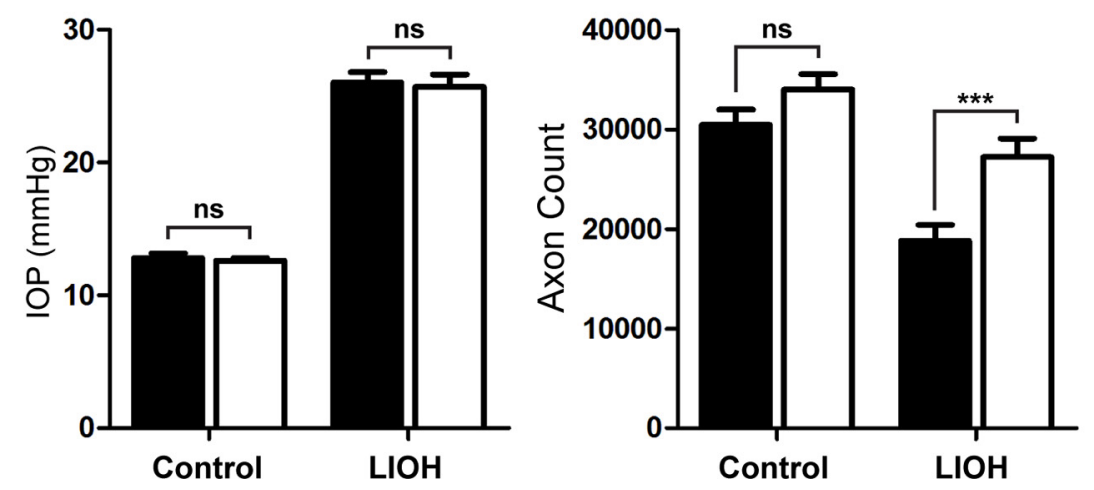

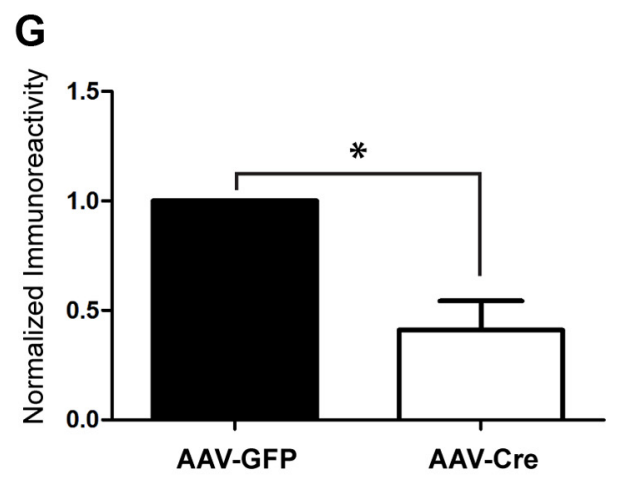

Figure 10. AAV-Cre-mediated deletion of NR1 attenuated RGC axon loss after LIOH. $\boldsymbol{A}-\boldsymbol{F}$, Reduced glutamate receptor activity following AAV-Cre injection in NR1-f mice. AGB was injected subconjunctivally $3 \mathrm{~d}$ after $\mathrm{LIOH}$. Robust AGB labeling was detected at the ONH of the AAV-GFP group $(\boldsymbol{A})$. $\beta$-III Tubulin staining $(\boldsymbol{B}, \boldsymbol{E})$ indicated the location of axonal labeling. The level of $A G B$ immunoreactivity was decreased by AAV-Cre injection (D). In particular, AGB staining was diminished in $\beta$-III tubulin ${ }^{+}$axons, while the intensity of glial signal remained comparable to the AAV-GFP control (F). G, AGB immunoreactivity over RGC axons was quantified and found to be significantly reduced by AAV-Cre compared to AAV-GFP. $n=4$ experiments. $\boldsymbol{H}, \boldsymbol{I}$, Axon counting in PPD-stained optic nerve cross-sections of NR1-f mice. No difference in IOP elevation induced by LIOH was found between the AAV-Cre and AAV-GFP groups (H). AAV-Cre injection significantly increased the number of surviving axons 2 weeks after $\mathrm{LIOH}(\boldsymbol{I})$. Scale bar: (in $\boldsymbol{F}) \boldsymbol{A}-\boldsymbol{F}, 50 \mu \mathrm{m} . n=20$ animals. ${ }^{*} p<0.05$; ${ }^{* * *} p<0.001$.

permeation and accumulation in axons after NR1 knockdown should be reduced by an amount proportional to the contribution of NMDA receptor activity to overall ionotropic receptor activation. In B6 albino NR1-f eyes injected with AAV-GFP, AGB permeation after $\mathrm{LIOH}$ resulted in robust labeling of $\mathrm{ONH}$ axons and glia (Fig. 10A). In contrast, AAV-Cre injection led to a re-

(Figure legend continued.) $\quad(\boldsymbol{P}) . S-U$, Quantitative analysis indicated the reduction in VGLUT2 $(\boldsymbol{S})$, glutamate $(\boldsymbol{T})$, and axonal AGB $(\boldsymbol{U})$ signals by AAV-Cre were statistically significant. $n=4$ for VGLUT2, 5 for glutamate, and 3 for AGB experiments. ${ }^{*} p<0.05$; ${ }^{* * *} p<0.001$. V-X, AAV-Cre-mediated deletion of VGLUT2 attenuated RGC axon loss after LIOH. Representative PPD-stained optic nerve cross-sections are shown in $\boldsymbol{V}$. The non- $\mathrm{LIOH}$ control sections were indistinguishable in the AAV-GFP and AAV-Cre conditions. Significant axon dropout can be observed in the AAV-GFP condition 2 weeks after $\mathrm{LIOH}$. AAV-Cre injection resulted in less RGC axon degeneration and more morphologically normal axons. There was no difference in IOP elevation induced by $\mathrm{LIOH}$ in AAV-Cre and AAV-GFP animals ( $\boldsymbol{W}$ ). AAV-Cre injection significantly increased the number of surviving axons 2 weeks after LIOH in VGLUT2-f mice $(X) . n=10$ for PPD experiment. ns, Not significant. ${ }^{* *} p<0.01$. Scale bars: $\boldsymbol{F}$ (for $\boldsymbol{A}-\boldsymbol{F}$ ), $\boldsymbol{L}$ (for $\boldsymbol{G}-\boldsymbol{L}$ ), $\boldsymbol{R}$ (for $M-R), 50 \mu \mathrm{m} ; V, 10 \mu \mathrm{m}$. duction of AGB signal in $\beta$-III tubulin ${ }^{+}$axons by $60 \%$ (Fig. $10 F, G)$. Of note, AGB staining in the neighboring glial cells remained relatively strong. These findings were consistent with the restricted deletion of NR1 in only RGCs. Since the AMPA receptor subunits GluR1 and GluR2 were also found to be expressed on RGC axons, the remaining AGB signal present in axons could be accounted for by AMPA receptors.

AAV-injected NR1-f mice were subjected to the analysis of optic nerve axon number after LIOH. IOP elevation was comparable between the AAV-GFP and AAV-Cre treatment groups (Fig. $10 H$ ). The morphology of PPD-stained optic nerve crosssections resembled that observed in the VGLUT2-f experiments. Optic nerve axon counts were similar between non-LIOHtreated control animals injected with either AAV vector (Fig. $10 I)$. LIOH reduced RGC axon count to $62 \%$ of control level in the AAV-GFP group after 2 weeks. AAV-Cre-mediated deletion of NR1 resulted in significant sparing of RGC axons to $80 \%$ of the level observed in non-LIOH-treated control animals (Fig. 10I; $p<0.001$ for AAV-Cre vs GFP). These data indicated that inter- 
ference with NMDA glutamate receptor activation in RGCs promoted axonal survival in experimental glaucoma.

\section{Discussion}

In the present study, we provide evidence for previously unsuspected ectopic vesicular glutamate release as well as glutamate sensitivity in RGC axons at the $\mathrm{ONH}$ of mice with laser-induced glaucoma. The data showed that synaptic components such as SV2, VGLUT2, glutamate, and Bassoon as well as synaptophysinpositive vesicles all accumulated ectopically within RGC axons at the ONH $2 \mathrm{~d}$ after IOP elevation. Live tissue detection of lumenal synaptotagmin epitopes as well as enzymatic assays for glutamate demonstrated ectopic vesicle exocytosis and local release of glutamate. GluR1, GluR2, and NR1 receptors were detected on RGC axons as well as astrocytes at the LIOH-treated ONH, and AGB permeation assays indicated that both cellular elements can respond to local glutamate release. In vivo pharmacological blockade of glutamate signaling at the $\mathrm{ONH}$ of mice with experimental glaucoma resulted in enhanced axon survival. AAV-mediated conditional deletion of VGLUT2 or NR1 specifically in RGCs showed that the elimination of either RGC glutamatergic vesicular loading or NMDA receptor signaling resulted in increased axon survival in LIOH-treated animals. These findings support a model in which RGC axons responding to $\mathrm{LIOH}$-induced glaucomatous insults at the $\mathrm{ONH}$ act as both the source of ectopic glutamate vesicular release and of glutamate sensitivity, thus potentially contributing to a cascading mechanism underlying the progressive RGC axon dropout associated with this disease.

\section{Glutamate release by axons at the $\mathrm{ONH}$}

The glutamate-mediated mechanism for glaucomatous RGC axon loss proposed here differs considerably from a previous model of glutamate excitotoxicity in glaucoma, in which dying RGC somas in the retina release and cause a buildup of glutamate within the vitreous cavity, leading to secondary degeneration of other RGCs. This earlier proposed mechanism has been questioned since the initial findings of raised intravitreal glutamate concentration have not been confirmed, and the presence of diffusible glutamate throughout the vitreous cavity is difficult to reconcile with the characteristic patchy loss of RGCs in the glaucomatous retina, in which affected and unaffected regions abut each other directly (Jakobs et al., 2005; Schlamp et al., 2006; Howell et al., 2007).

Our current findings are distinct in three important aspects: site of synaptic component accumulation and glutamate release, timing, and the mechanism of release. First, the accumulation of ectopic vesicles and glutamate induced by $\mathrm{LIOH}$ was most prominent at the $\mathrm{ONH}$, and to a much lesser extent in the adjoining retina or myelinated optic nerve regions. Second, this phenomenon occurred relatively early in the disease process $(\sim 2 \mathrm{~d}$ after $\mathrm{LIOH})$, before apparent RGC soma loss sets in between 1 and 2 weeks after pressure elevation (Fu and Sretavan, 2010). Third, glutamate appeared to be released via a vesicular mechanism from axon segments within the glaucomatous $\mathrm{ONH}$, as opposed to being passively released into the vitreous environment by dying RGCs in the retina. While it is unclear how much this ectopic ONH vesicular release resembles normal synaptic glutamate release in terms of regulatory and energetic mechanisms, the data indicated that it is VGLUT2 dependent and occurs in the presence of many components of the normal synaptic release machinery.

\section{Ectopic release and axonal glutamate receptors}

The release of neurotransmitter-containing vesicles from nonsynaptic axon regions, although counter to the dictum of vesicle release from specialized presynaptic active zones, is consistent with accumulating evidence suggesting that exocytosis occurs at ectopic locations distant from conventional synapses in many CNS regions, including the optic nerve and retinal bipolar cell terminals (Ceccarelli et al., 1979; Zenisek et al., 2000; Lenzi et al., 2002; Matsui and Jahr, 2003, 2006; Coggan et al., 2005; Kukley et al., 2007; Ziskin et al., 2007; Thyssen et al., 2010). These previous studies suggested that ectopic release plays a role in normal physiology by mediating synaptic transmission and axon-glia communication and strongly argue that morphologically distinct specialization is not a prerequisite for exocytosis.

Our ultrastructural data demonstrated the presence of synaptophysin-positive vesicles that resemble pleiomorphic vesicles described previously in axons (Kraszewski et al., 1995; Ahmari et al., 2000) and interpreted as SV precursors that undergo exoendocytosis without synaptic contacts (Matteoli et al., 1992; Kraszewski et al., 1995; Dai and Peng, 1998; Zakharenko et al., 1999; Krueger et al., 2003). In LIOH, the demonstration of membranebound organelles containing SV components and vesicular glutamate release at the $\mathrm{ONH}$ indicated that ectopic neurotransmitter release at nonsynaptic sites may also be a feature of pathological conditions.

Our data also showed that RGC axons at the unmyelinated $\mathrm{ONH}$ were receptive to the released glutamate. After $\mathrm{LIOH}$ induction, RGC axons expressed the AMPA receptor subunits GluR1 and GluR2 as well as the essential NMDA receptor subunit NR1. Although there was substantial AGB permeation into glaucomatous RGC axons, demonstrating robust ionotropic glutamate receptor activity, our current data do not differentiate between AGB influx into axons via AMPA, kainite, or NMDA receptors.

Previous studies have demonstrated that white matter axons can respond to AMPA or kainate receptor agonists, and excessive stimulation of these receptors can lead to axonal damage (Matute, 1998; Fowler et al., 2003; Ouardouz et al., 2006, 2009a,b; Bakiri et al., 2009; Matute, 2010). The expression of NMDA receptor subunits in rodent RGC somas has been well established by mRNA detection (Brandstätter et al., 1994; Watanabe et al., 1994; Jakobs et al., 2007), immunohistochemistry (Fletcher et al., 2000; Gründer et al., 2000; Kalloniatis et al., 2004), and electrophysiology (Chen and Diamond, 2002). NR1 expression (Aoki et al., 1994; Gracy and Pickel, 1995) and function (Vorwerk et al., 2001; Bardoni et al., 2004; Duguid and Smart, 2004) on axons have also been documented. Our data demonstrated that NR1 was expressed at a low level in RGC axons at the normal ONH and became strongly upregulated after $\mathrm{LIOH}$ treatment. AAV-Cremediated deletion of NR1 from RGCs reduced AGB signal in LIOH-treated axons, indicating that NMDA receptors account for at least part of the ionotropic glutamate receptor activity. The significant axonal protection conferred by the in vivo genetic deletion of NR1 from RGCs supported a role of NMDA receptors in glaucomatous axon degeneration. The contributions from AMPA and kainite receptors remain to be further elucidated.

\section{Sectoral patterns of RGC damage in glaucoma}

Throughout this study, we repeatedly observed highly localized patterns of ectopic glutamate-related pathology in $\mathrm{LIOH}$ glaucoma. At the overall anatomic level, ectopic vesicle accumulation was highly localized to axon segments within the unmyelinated $\mathrm{ONH}$ and was much less apparent in the myelinated portion of the optic nerve or in RGC somas in the retina. At the cellular level, there was substantial heterogeneity among RGC axons at the $\mathrm{ONH}$, with individual groups of axons heavily laden with ectopic synaptic components, while adjacent groups appeared unaf- 
fected. Heterogeneity extended even to the subcellular level, as different locations along the same axon appeared to be differentially affected, and glutamate accumulation and receptor activity were often distributed in discrete hot spots along a process.

Previous findings in the $\mathrm{LIOH}$ mouse model (Fu and Sretavan, 2010) and in several other glaucoma models (Jakobs et al., 2005; Schlamp et al., 2006; Howell et al., 2007; Soto et al., 2010) have demonstrated that RGC degeneration in the retina occurs in sectoral patterns, in which areas of dense soma loss reside next to relatively unaffected regions. The present findings may provide insight into this phenomenon, since focal damage affecting distinct axon bundles within the $\mathrm{ONH}$ can be expected to ultimately lead to a patchy pattern of RGC loss in the retina. It remains to be determined whether RGC axons sustaining glutamate-induced damage respond by acting as further sources of ectopic glutamate release, thus propagating injury to neighboring axons in a cascading fashion.

\section{Applicability to other models of glaucoma}

The progression of glaucomatous RGC damage in $\mathrm{LIOH}$ follows a more rapid time course than that in DBA/2J mice (Libby et al., 2005b; Fu and Sretavan, 2010). However in both mouse models, as in human glaucoma patients, damage to the visual system is confined to RGCs and does not affect other retina cell types. The $\mathrm{LIOH}$ model permits precise control over the timing of IOP elevation, and thus disease onset. Such control was particularly important for characterizing the $\mathrm{ONH}$ accumulation of synaptic components demonstrated in this study, as these events occurred relatively early only $\sim 2$ $\mathrm{d}$ after $\mathrm{LIOH}$ induction. Furthermore, the experiments using pharmacological blockade and AAV-mediated gene deletions required precise timing with disease induction and would have been difficult to execute otherwise. Our findings demonstrating the role of ectopic glutamate release and glutamate sensitivity in glaucomatous axon loss could conceivably be more difficult to recognize in DBA/2J mice or in human patients, in which disease onset is less well defined. Nevertheless, we have observed ectopic SV protein accumulation at the $\mathrm{ONH}$ of 10- to 12-month-old DBA/2J mice (our unpublished data), suggesting that vesicular glutamate release might also be relevant in this more chronic progressive model of glaucoma. Since the present study suggests that mechanisms of neurotransmitter release operating ectopically at the glaucomatous $\mathrm{ONH}$ may provide useful entries for therapeutic intervention, future work should be directed at validation across additional animal models and in human disease.

\section{References}

Acosta ML, Chua J, Kalloniatis M (2007) Functional activation of glutamate ionotropic receptors in the developing mouse retina. J Comp Neurol 500:923-941.

Acosta ML, Bumsted O'Brien KM, Tan SS, Kalloniatis M (2008) Emergence of cellular markers and functional ionotropic glutamate receptors on tangentially dispersed cells in the developing mouse retina. J Comp Neurol 506:506-523.

Ahmari SE, Buchanan J, Smith SJ (2000) Assembly of presynaptic active zones from cytoplasmic transport packets. Nat Neurosci 3:445-451.

Anderson DR, Hendrickson A (1974) Effect of intraocular pressure on rapid axoplasmic transport in monkey optic nerve. Invest Ophthalmol 13:771783.

Aoki C, Venkatesan C, Go CG, Mong JA, Dawson TM (1994) Cellular and subcellular localization of NMDA-R1 subunit immunoreactivity in the visual cortex of adult and neonatal rats. J Neurosci 14:5202-5222.

Ayoub GS, Dorst K (1998) Imaging of glutamate release from the goldfish retinal slice. Vision Res 38:2909-2912.

Ayoub GS, Grutsis S, Simko H (1998) Imaging of endogenous neurotransmitter release. J Neurosci Methods 81:113-119.

Bakiri Y, Burzomato V, Frugier G, Hamilton NB, Káradóttir R, Attwell D (2009) Glutamatergic signaling in the brain's white matter. Neuroscience 158:266-274.
Bardoni R, Torsney C, Tong CK, Prandini M, MacDermott AB (2004) Presynaptic NMDA receptors modulate glutamate release from primary sensory neurons in rat spinal cord dorsal horn. J Neurosci 24:2774-2781.

Brandstätter JH, Hartveit E, Sassoe-Pognetto M, Wassle H (1994) Expression of NMDA and high-affinity kainate receptor subunit mRNAs in the adult rat retina. Eur J Neurosci 6:1100-1112.

Brose N, Huntley GW, Stern-Bach Y, Sharma G, Morrison JH, Heinemann SF (1994) Differential assembly of coexpressed glutamate receptor subunits in neurons of rat cerebral cortex. J Biol Chem 269:16780-16784.

Brown NL, Patel S, Brzezinski J, Glaser T (2001) Math5 is required for retinal ganglion cell and optic nerve formation. Development 128:2497-2508.

Buckingham BP, Inman DM, Lambert W, Oglesby E, Calkins DJ, Steele MR, Vetter ML, Marsh-Armstrong N, Horner PJ (2008) Progressive ganglion cell degeneration precedes neuronal loss in a mouse model of glaucoma. J Neurosci 28:2735-2744

Carlton SM, Hargett GL, Coggeshall RE (1995) Localization and activation of glutamate receptors in unmyelinated axons of rat glabrous skin. Neurosci Lett 197:25-28.

Ceccarelli B, Grohovaz F, Hurlbut WP (1979) Freeze-fracture studies of frog neuromuscular junctions during intense release of neurotransmitter. II. Effects of electrical stimulation and high potassium. J Cell Biol 81:178 192.

Chang YC, Chiao CC (2008) Localization and functional mapping of AMPA receptor subunits in the developing rabbit retina. Invest Ophthalmol Vis Sci 49:5619-5628.

Chen S, Diamond JS (2002) Synaptically released glutamate activates extrasynaptic NMDA receptors on cells in the ganglion cell layer of rat retina. J Neurosci 22:2165-2173.

Cheng L, Sapieha P, Kittlerova P, Hauswirth WW, Di Polo A (2002) TrkB gene transfer protects retinal ganglion cells from axotomy-induced death in vivo. J Neurosci 22:3977-3986.

Coggan JS, Bartol TM, Esquenazi E, Stiles JR, Lamont S, Martone ME, Berg DK, Ellisman MH, Sejnowski TJ (2005) Evidence for ectopic neurotransmission at a neuronal synapse. Science 309:446-451.

Coggeshall RE, Carlton SM (1998) Ultrastructural analysis of NMDA, AMPA, and kainate receptors on unmyelinated and myelinated axons in the periphery. J Comp Neurol 391:78-86.

Costes SV, Daelemans D, Cho EH, Dobbin Z, Pavlakis G, Lockett S (2004) Automatic and quantitative measurement of protein-protein colocalization in live cells. Biophys J 86:3993-4003.

Dai Z, Peng HB (1998) Fluorescence microscopy of calcium and synaptic vesicle dynamics during synapse formation in tissue culture. Histochem J 30:189-196.

Davies DC, McCoubrie P, McDonald B, Jobst KA (1995) Myelinated axon number in the optic nerve is unaffected by Alzheimer's disease. Br J Ophthalmol 79:596-600.

Duguid IC, Smart TG (2004) Retrograde activation of presynaptic NMDA receptors enhances GABA release at cerebellar interneuron-Purkinje cell synapses. Nat Neurosci 7:525-533.

Fletcher EL, Hack I, Brandstätter JH, Wässle H (2000) Synaptic localization of NMDA receptor subunits in the rat retina. J Comp Neurol 420:98-112.

Fowler JH, McCracken E, Dewar D, McCulloch J (2003) Intracerebral injection of AMPA causes axonal damage in vivo. Brain Res 991:104-112.

Fu CT, Sretavan D (2010) Laser-induced ocular hypertension in albino CD-1 mice. Invest Ophthalmol Vis Sci 51:980-990.

Fu CT, Sretavan D (2011) Involvement of EphB/ephrin-B signaling in axonal survival in mouse experimental glaucoma. Invest Ophthalmol Vis Sci.

Gerber SH, Rah JC, Min SW, Liu X, de Wit H, Dulubova I, Meyer AC, Rizo J, Arancillo M, Hammer RE, Verhage M, Rosenmund C, Südhof TC (2008) Conformational switch of syntaxin- 1 controls synaptic vesicle fusion. Science 321:1507-1510.

Gracy KN, Pickel VM (1995) Comparative ultrastructural localization of the NMDAR1 glutamate receptor in the rat basolateral amygdala and bed nucleus of the stria terminalis. J Comp Neurol 362:71-85.

Gründer T, Kohler K, Kaletta A, Guenther E (2000) The distribution and developmental regulation of NMDA receptor subunit proteins in the outer and inner retina of the rat. J Neurobiol 44:333-342.

Haverkamp S, Wässle H (2000) Immunocytochemical analysis of the mouse retina. J Comp Neurol 424:1-23.

Hellström M, Ruitenberg MJ, Pollett MA, Ehlert EM, Twisk J, Verhaagen J, Harvey AR (2009) Cellular tropism and transduction properties of 
seven adeno-associated viral vector serotypes in adult retina after intravitreal injection. Gene Ther 16:521-532.

Hnasko TS, Chuhma N, Zhang H, Goh GY, Sulzer D, Palmiter RD, Rayport S, Edwards RH (2010) Vesicular glutamate transport promotes dopamine storage and glutamate corelease in vivo. Neuron 65:643-656.

Howell GR, Libby RT, Jakobs TC, Smith RS, Phalan FC, Barter JW, Barbay JM, Marchant JK, Mahesh N, Porciatti V, Whitmore AV, Masland RH, John SW (2007) Axons of retinal ganglion cells are insulted in the optic nerve early in DBA/2J glaucoma. J Cell Biol 179:1523-1537.

Innocenti B, Parpura V, Haydon PG (2000) Imaging extracellular waves of glutamate during calcium signaling in cultured astrocytes. J Neurosci 20:1800-1808.

Ivanova E, Pan ZH (2009) Evaluation of the adeno-associated virus mediated long-term expression of channelrhodopsin-2 in the mouse retina. Mol Vis 15:1680-1689.

Iwasato T, Datwani A, Wolf AM, Nishiyama H, Taguchi Y, Tonegawa S, Knöpfel T, Erzurumlu RS, Itohara S (2000) Cortex-restricted disruption of NMDAR1 impairs neuronal patterns in the barrel cortex. Nature 406:726-731.

Jakobs TC, Libby RT, Ben Y, John SW, Masland RH (2005) Retinal ganglion cell degeneration is topological but not cell type specific in DBA/2J mice. J Cell Biol 171:313-325.

Jakobs TC, Ben Y, Masland RH (2007) Expression of mRNA for glutamate receptor subunits distinguishes the major classes of retinal neurons, but is less specific for individual cell types. Mol Vis 13:933-948.

Johnson EC, Jia L, Cepurna WO, Doser TA, Morrison JC (2007) Global changes in optic nerve head gene expression after exposure to elevated intraocular pressure in a rat glaucoma model. Invest Ophthalmol Vis Sci 48:3161-3177.

Johnson EC, Guo Y, Cepurna WO, Morrison JC (2009) Neurotrophin roles in retinal ganglion cell survival: lessons from rat glaucoma models. Exp Eye Res 88:808-815.

Kalloniatis M, Tomisich G, Wellard JW, Foster LE (2002) Mapping photoreceptor and postreceptoral labelling patterns using a channel permeable probe (agmatine) during development in the normal and RCS rat retina. Vis Neurosci 19:61-70.

Kalloniatis M, Sun D, Foster L, Haverkamp S, Wässle H (2004) Localization of NMDA receptor subunits and mapping NMDA drive within the mammalian retina. Vis Neurosci 21:587-597.

Kashani AH, Chen BM, Grinnell AD (2001) Hypertonic enhancement of transmitter release from frog motor nerve terminals: $\mathrm{Ca} 2+$ independence and role of integrins. J Physiol 530:243-252.

Kraszewski K, Mundigl O, Daniell L, Verderio C, Matteoli M, De Camilli P (1995) Synaptic vesicle dynamics in living cultured hippocampal neurons visualized with CY3-conjugated antibodies directed against the lumenal domain of synaptotagmin. J Neurosci 15:4328-4342.

Krueger SR, Kolar A, Fitzsimonds RM (2003) The presynaptic release apparatus is functional in the absence of dendritic contact and highly mobile within isolated axons. Neuron 40:945-957.

Kukley M, Capetillo-Zarate E, Dietrich D (2007) Vesicular glutamate release from axons in white matter. Nat Neurosci 10:311-320.

Lenzi D, Crum J, Ellisman MH, Roberts WM (2002) Depolarization redistributes synaptic membrane and creates a gradient of vesicles on the synaptic body at a ribbon synapse. Neuron 36:649-659.

Libby RT, Li Y, Savinova OV, Barter J, Smith RS, Nickells RW, John SW (2005a) Susceptibility to neurodegeneration in a glaucoma is modified by Bax gene dosage. PLoS Genet 1:17-26.

Libby RT, Anderson MG, Pang IH, Robinson ZH, Savinova OV, Cosma IM, Snow A, Wilson LA, Smith RS, Clark AF, John SW (2005b) Inherited glaucoma in DBA/2J mice: pertinent disease features for studying the neurodegeneration. Vis Neurosci 22:637-648.

Madisen L, Zwingman TA, Sunkin SM, Oh SW, Zariwala HA, Gu H, Ng LL, Palmiter RD, Hawrylycz MJ, Jones AR, Lein ES, Zeng H (2010) A robust and high-throughput Cre reporting and characterization system for the whole mouse brain. Nat Neurosci 13:133-140.

Maguire G, Simko H, Weinreb RN, Ayoub G (1998) Transport-mediated release of endogenous glutamate in the vertebrate retina. Pflugers Arch 436:481-484.

Malik JM, Shevtsova Z, Bähr M, Kügler S (2005) Long-term in vivo inhibition of CNS neurodegeneration by Bcl-XL gene transfer. Mol Ther 11: 373-381.
Marc RE (1999a) Kainate activation of horizontal, bipolar, amacrine, and ganglion cells in the rabbit retina. J Comp Neurol 407:65-76.

Marc RE (1999b) Mapping glutamatergic drive in the vertebrate retina with a channel-permeant organic cation. J Comp Neurol 407:47-64.

Marc RE, Kalloniatis M, Jones BW (2005) Excitation mapping with the organic cation AGB2+. Vision Res 45:3454-3468.

Martin KR, Klein RL, Quigley HA (2002) Gene delivery to the eye using adeno-associated viral vectors. Methods 28:267-275.

Matsui K, Jahr CE (2003) Ectopic release of synaptic vesicles. Neuron 40:1173-1183.

Matsui K, Jahr CE (2006) Exocytosis unbound. Curr Opin Neurobiol 16:305-311.

Matteoli M, Takei K, Perin MS, Südhof TC, De Camilli P (1992) Exoendocytotic recycling of synaptic vesicles in developing processes of cultured hippocampal neurons. J Cell Biol 117:849-861.

Matute C (1998) Characteristics of acute and chronic kainate excitotoxic damage to the optic nerve. Proc Natl Acad Sci U S A 95:10229-10234.

Matute C (2010) Calcium dyshomeostasis in white matter pathology. Cell Calcium 47:150-157.

Milner TA, Drake CT (2001) Ultrastructural evidence for presynaptic mu opioid receptor modulation of synaptic plasticity in NMDA-receptorcontaining dendrites in the dentate gyrus. Brain Res Bull 54:131-140.

Minckler DS, Tso MO, Zimmerman LE (1976) A light microscopic, autoradiographic study of axoplasmic transport in the optic nerve head during ocular hypotony, increased intraocular pressure, and papilledema. Am J Ophthalmol 82:741-757.

Moriyoshi K, Masu M, Ishii T, Shigemoto R, Mizuno N, Nakanishi S (1991) Molecular cloning and characterization of the rat NMDA receptor. Nature 354:31-37.

Morrison JC, Moore CG, Deppmeier LM, Gold BG, Meshul CK, Johnson EC (1997) A rat model of chronic pressure-induced optic nerve damage. Exp Eye Res 64:85-96.

Nakanishi S (1992) Molecular diversity of glutamate receptors and implications for brain function. Science 258:597-603.

Ouardouz M, Malek S, Coderre E, Stys PK (2006) Complex interplay between glutamate receptors and intracellular $\mathrm{Ca} 2+$ stores during ischaemia in rat spinal cord white matter. J Physiol 577:191-204.

Ouardouz M, Coderre E, Zamponi GW, Hameed S, Yin X, Trapp BD, Stys PK (2009a) Glutamate receptors on myelinated spinal cord axons: II. AMPA and GluR5 receptors. Ann Neurol 65:160-166.

Ouardouz M, Coderre E, Basak A, Chen A, Zamponi GW, Hameed S, Rehak R, Yin X, Trapp BD, Stys PK (2009b) Glutamate receptors on myelinated spinal cord axons: I. GluR6 kainate receptors. Ann Neurol 65:151-159.

Park KK, Liu K, Hu Y, Smith PD, Wang C, Cai B, Xu B, Connolly L, Kramvis I, Sahin M, He Z (2008) Promoting axon regeneration in the adult CNS by modulation of the PTEN/mTOR pathway. Science 322:963-966.

Pease ME, McKinnon SJ, Quigley HA, Kerrigan-Baumrind LA, Zack DJ (2000) Obstructed axonal transport of BDNF and its receptor TrkB in experimental glaucoma. Invest Ophthalmol Vis Sci 41:764-774.

Pease ME, Zack DJ, Berlinicke C, Bloom K, Cone F, Wang Y, Klein RL, Hauswirth WW, Quigley HA (2009) Effect of CNTF on retinal ganglion cell survival in experimental glaucoma. Invest Ophthalmol Vis Sci 50:2194-2200.

Quigley HA (1996) Number of people with glaucoma worldwide. Br J Ophthalmol 80:389-393.

Quigley HA, Addicks EM (1980) Chronic experimental glaucoma in primates. II. Effect of extended intraocular pressure elevation on optic nerve head and axonal transport. Invest Ophthalmol Vis Sci 19:137-152.

Quigley HA, Addicks EM, Green WR, Maumenee AE (1981) Optic nerve damage in human glaucoma. II. The site of injury and susceptibility to damage. Arch Ophthalmol 99:635-649.

Quigley HA, McKinnon SJ, Zack DJ, Pease ME, Kerrigan-Baumrind LA, Kerrigan DF, Mitchell RS (2000) Retrograde axonal transport of BDNF in retinal ganglion cells is blocked by acute IOP elevation in rats. Invest Ophthalmol Vis Sci 41:3460-3466.

Rohrer B, Blanco R, Marc RE, Lloyd MB, Bok D, Schneeweis DM, Reichardt LF (2004) Functionally intact glutamate-mediated signaling in bipolar cells of the TRKB knockout mouse retina. Vis Neurosci 21:703-713.

Rosenmund C, Stevens CF (1996) Definition of the readily releasable pool of vesicles at hippocampal synapses. Neuron 16:1197-1207.

Schlamp CL, Li Y, Dietz JA, Janssen KT, Nickells RW (2006) Progressive ganglion cell loss and optic nerve degeneration in DBA/2J mice is variable and asymmetric. BMC Neurosci 7:66. 
Shen Y, Liu XL, Yang XL (2006) N-methyl-D-aspartate receptors in the retina. Mol Neurobiol 34:163-179.

Siegel SJ, Brose N, Janssen WG, Gasic GP, Jahn R, Heinemann SF, Morrison JH (1994) Regional, cellular, and ultrastructural distribution of $\mathrm{N}$-methyl-D-aspartate receptor subunit 1 in monkey hippocampus. Proc Natl Acad Sci U S A 91:564-568.

Soto I, Oglesby E, Buckingham BP, Son JL, Roberson ED, Steele MR, Inman DM, Vetter ML, Horner PJ, Marsh-Armstrong N (2008) Retinal ganglion cells downregulate gene expression and lose their axons within the optic nerve head in a mouse glaucoma model. J Neurosci 28:548-561.

Soto I, Pease ME, Son JL, Shi X, Quigley HA, Marsh-Armstrong N (2010) Retinal ganglion cell loss in a rat ocular hypertension model is sectorial and involves early optic nerve axon loss. Invest Ophthalmol Vis Sci.

South SM, Kohno T, Kaspar BK, Hegarty D, Vissel B, Drake CT, Ohata M, Jenab S, Sailer AW, Malkmus S, Masuyama T, Horner P, Bogulavsky J, Gage FH, Yaksh TL, Woolf CJ, Heinemann SF, Inturrisi CE (2003) A conditional deletion of the NR1 subunit of the NMDA receptor in adult spinal cord dorsal horn reduces NMDA currents and injury-induced pain. J Neurosci 23:5031-5040.

Sun D, Kalloniatis M (2004) Quantification of amino acid neurochemistry secondary to NMDA or betaxolol application. Clin Experiment Ophthalmol 32:505-517.

Sun D, Kalloniatis M (2006) Mapping glutamate responses in immunocytochemically identified neurons of the mouse retina. J Comp Neurol 494:686-703.

Sun D, Rait JL, Kalloniatis M (2003) Inner retinal neurons display differential responses to $\mathrm{N}$-methyl-D-aspartate receptor activation. J Comp Neurol 465:38-56.

Sun D, Vingrys AJ, Kalloniatis M (2007a) Metabolic and functional profiling of the normal rat retina. J Comp Neurol 505:92-113.

Sun D, Bui BV, Vingrys AJ, Kalloniatis M (2007b) Alterations in photoreceptor-bipolar cell signaling following ischemia/reperfusion in the rat retina. J Comp Neurol 505:131-146.

Thyssen A, Hirnet D, Wolburg H, Schmalzing G, Deitmer JW, Lohr C (2010) Ectopic vesicular neurotransmitter release along sensory axons mediates neurovascular coupling via glial calcium signaling. Proc Natl Acad Sci U S A 107:15258-15263.

Tsien JZ, Huerta PT, Tonegawa S (1996) The essential role of hippocampal CA1 NMDA receptor-dependent synaptic plasticity in spatial memory. Cell 87:1327-1338.

Turner TJ (2004) Nicotine enhancement of dopamine release by a calciumdependent increase in the size of the readily releasable pool of synaptic vesicles. J Neurosci 24:11328-11336.

Vorwerk CK, Naskar R, Schuettauf F, Zurakowski D, McDermott LM, Quinto KM, Dreyer EB (2001) Excitotoxicity can be mediated through an interaction within the optic nerve; activation of cell body NMDA receptors is not required. Vet Ophthalmol 4:201-204.

Watanabe M, Rutishauser U, Silver J (1991) Formation of the retinal ganglion cell and optic fiber layers. J Neurobiol 22:85-96.

Watanabe M, Mishina M, Inoue Y (1994) Differential distributions of the NMDA receptor channel subunit mRNAs in the mouse retina. Brain Res 634:328-332.

Zakharenko S, Chang S, O'Donoghue M, Popov SV (1999) Neurotransmitter secretion along growing nerve processes: comparison with synaptic vesicle exocytosis. J Cell Biol 144:507-518.

Zenisek D, Steyer JA, Almers W (2000) Transport, capture and exocytosis of single synaptic vesicles at active zones. Nature 406:849-854.

Zhong L, Bradley J, Schubert W, Ahmed E, Adamis AP, Shima DT, Robinson GS, Ng YS (2007) Erythropoietin promotes survival of retinal ganglion cells in DBA/2J glaucoma mice. Invest Ophthalmol Vis Sci 48:1212-1218.

Ziskin JL, Nishiyama A, Rubio M, Fukaya M, Bergles DE (2007) Vesicular release of glutamate from unmyelinated axons in white matter. Nat Neurosci 10:321-330. 